\title{
The comparison of MODIS-Aqua (C5) and CALIOP (V2 \& V3) aerosol optical depth
}

\author{
J. Redemann ${ }^{1}$, M. A. Vaughan ${ }^{2}$, Q. Zhang ${ }^{1}$, Y. Shinozuka ${ }^{1}$, P. B. Russell ${ }^{3}$, J. M. Livingston ${ }^{4}$, M. Kacenelenbogen ${ }^{1}$, and \\ L. A. Remer $^{5}$ \\ ${ }^{1}$ BAER Institute/NASA Ames, 4742 Suffolk Ct., Ventura, CA 93003, USA \\ ${ }^{2}$ NASA Langley Research Center, Hampton, VA 23681, USA \\ ${ }^{3}$ NASA Ames Research Center, MS 245-5, Bldg. 245, P.O. Box 1, Moffett Field, CA 94035, USA \\ ${ }^{4}$ SRI, International, 333 Ravenswood Ave., Menlo Park, CA 94025, USA \\ ${ }^{5}$ NASA Goddard Space Flight Center, code 613.2, Bldg. 33, Greenbelt, MD 20771, USA
}

Correspondence to: J. Redemann (jens.redemann-1@nasa.gov)

Received: 11 July 2011 - Published in Atmos. Chem. Phys. Discuss.: 16 August 2011

Revised: 18 February 2012 - Accepted: 5 March 2012 - Published: 28 March 2012

\begin{abstract}
We assess the consistency between instantaneously collocated level-2 aerosol optical depth (AOD) retrievals from MODIS-Aqua (C5) and CALIOP (Version $2 \& 3$ ), comparing the standard MODIS AOD (MYD04_L2) data to the AOD calculated from CALIOP aerosol extinction profiles for both the previous release (V2) and the latest release (V3) of CALIOP data. Based on data collected in January 2007, we investigate the most useful criteria for screening the MODIS and CALIOP retrievals to achieve the best agreement between the two data sets. Applying these criteria to eight months of data (Jan, Apr, Jul, Oct 2007 and 2009), we find an order of magnitude increase for the CALIOP V3 data density (by comparison to V2), that is generally accompanied by equal or better agreement with MODIS AOD. Differences in global, monthly mean, over-ocean AOD (532 nm) between CALIOP and MODIS range between 0.03 and 0.04 for CALIOP V3, with CALIOP generally biased low, when all available data from both sensors are considered. Rootmean-squares (RMS) differences in instantaneously collocated AOD retrievals by the two instruments are reduced from values ranging between 0.14 and 0.19 using the unscreened V3 data to values ranging from 0.09 to 0.1 for the screened data. A restriction to scenes with cloud fractions less than $1 \%$ (as defined in the MODIS aerosol retrievals) generally results in improved correlation $\left(R^{2}>0.5\right)$, except for the month of July when correlations remain relatively lower. Regional assessments show hot spots in disagreement between the two sensors in Asian outflow during April and off the coast of South Africa in July.
\end{abstract}

\section{Introduction}

Aerosols introduce a major uncertainty in predictions of possible future changes to the Earth system in general, and its climate in particular, owing to the incomplete knowledge of aerosol physicochemical properties and their spatial distribution. The IPCC-2007 estimates of the direct aerosol radiative forcing (DARF) of climate are largely based on climate model simulations. Observationally-based estimates are sparse, and their mean result for DARF is about a factor of two larger than the mean of the model-based estimates (IPCC, 2007). A recent study by Myhre (2009) suggests that the differences between model- and observation-based estimates is largely due to a change in aerosol optical properties attributable to anthropogenic activity (i.e., a stronger increase in soot aerosols by comparison to purely scattering aerosols since pre-industrial times) not accounted for in the observation-based estimates. Myhre (2009) concludes that "remaining uncertainty (in DARF) is probably related to the vertical profiles of the aerosols and their location in relation to clouds".

Designated aerosol satellite sensors such as MODIS, MISR, CALIOP and OMI (Remer et al., 2005; Kaufman et al., 2002; Zhang et al., 2005; Torres et al., 2007; Winker et al., 2010) provide important contributions to our understanding of the effects of aerosols on climate. MODIS and MISR provide reliable retrievals of spectral AOD with reasonably well known uncertainties under most conditions (e.g., Kahn et al., 2010; Redemann et al., 2006, Levy et al., 2010; Kleidman et al., 2011), with particular strengths over oceans 
where surface reflectances are less uncertain than over land. OMI has begun to investigate aerosol absorption, although extensive validation of the absorption optical depth product is still to be undertaken (Torres et al., 2007; Satheesh et al., 2009). CALIOP provides vertical profiles of aerosol properties over a narrow swath $(\sim 90 \mathrm{~m})$ along the satellite ground track (Winker et al., 2007). It should be noted that we use the term aerosol "retrieval" in this paper to denote a data product that was inverted from an observation which is not a direct measurement of the aerosol property, but instead requires assumptions about specific aerosol properties such as the aerosol phase function or particle size distribution.

To provide the full complement of aerosol properties required to improve the accuracy of aerosol radiative effect calculations, these observations have to be combined effectively with each other and with suborbital aerosol measurements. For example, studies of aerosol direct radiative effects (DRE) depend critically on the vertical profile of radiative properties, yet CALIOP, which provides aerosol extinction profile retrievals, does so at only two wavelengths, and the maturity of these products is still low. Estimates of the semi-direct effect of aerosols depend on reliable measurements of aerosol absorption near the clouds whose developments they are affecting, yet OMI has a large foot-print and its observations become less reliable in cloudy environments (Satheesh et al., 2009; Livingston et al., 2009). Finally, estimates of aerosol indirect effects require detailed knowledge of aerosol activation processes in areas difficult to access with satellite sensors, e.g., below opaque clouds. Hence, it is paramount for the scientific community to develop techniques to combine the A-Train aerosol observations with each other and with auxiliary suborbital observations to improve the estimates of the specific aerosol properties relevant for the various processes governing aerosol-climate interactions.

Although a few studies combining MODIS, OMI and CALIOP observations exist (e.g., Jeong and Hsu, 2008), little is known about the degree of consistency between these data sets. The study presented here investigates the consistency between instantaneously collocated MODIS and CALIOP aerosol retrievals for globally distributed data in eight months (Jan, Apr, Jul, Oct 2007 and 2009). Investigating intra-annual differences allows us to study the impact of different regions and aerosol types on global mean AOD estimates, while studying the inter-annual differences gives insight into potential sensor calibration or performance changes. The most easily comparable observation between the two sensors, that is also relevant for aerosol radiative effects, is AOD, which MODIS provides at seven wavelengths over-ocean (one of which is extrapolated) and three wavelengths over-land (of which two hold no independent information), and which can be calculated from CALIOP profiles of aerosol extinction at $532 \mathrm{~nm}$ and $1064 \mathrm{~nm}$. We focus our discussions in Sect. 3 on the quantitative comparison of collocated AOD retrievals over-ocean, because the uncertainty and variability of MODIS over-ocean AOD retrievals is considerably less than over-land and well documented in the literature (e.g., Redemann et al., 2005, 2006, 2009a,c; Russell et al., 2007, Remer et al., 2005, 2008). Therefore, the over-ocean comparisons are more useful in identifying potential shortcomings in the retrievals from either sensor. Hence, we consider the MODIS over-ocean retrievals a standard that the CALIOP retrievals can be measured by and should agree with within uncertainties. We note that the CALIOP-MODIS AOD comparisons presented here are an imperfect tool to assess CALIOP data quality, because the MODIS retrievals themselves are subject to uncertainties that vary with cloud, surface and aerosol conditions, and because the daytime CALIOP measurements required are adversely affected by the high-intensity solar background signal. However, as previously noted by many investigators (e.g., Schuster et al., 2007), comparing CALIOP to AERONET retrievals is limited to a few hundred opportunities per year if reasonable collocation criteria are applied. Hence, the MODISCALIOP comparisons presented here, while imperfect, provide an opportunity for a statistically relevant assessment of the CALIOP-derived AOD against a data product with peerreviewed accuracy and limitations. Over-land comparisons are provided in our study only to assess whether or not there is consistency with the over-ocean retrievals as far as the geographical distribution of AOD differences between the two sensors is concerned. Kittaka et al. (2010) provide a similar analysis to the one presented in this paper. However, their study is restricted to CALIOP V2 retrievals, they do not distinguish between MODIS ocean and land retrievals, and their analysis is considerably more qualitative than the analysis described here. Oo and Holz (2011) analyzed the same data in 2007 as we did here, and found a slightly greater bias difference between MODIS and CALIOP AOD. However, their comparisons were screened very differently from our data set, and the fundamental result of a bias difference of $\sim 0.064$ between MODIS and CALIOP AOD is similar to ours.

\section{Data sets}

\subsection{MODIS-Aqua AOD}

MODIS-Aqua (Moderate Resolution Imaging Spectroradiometer) is one of six Earth-observing instruments aboard the Aqua satellite. The MODIS aerosol product (MYD04_L2 in the MODIS data product catalogue) is derived from radiance measurements in channels 1-7 and 20 of the 36 MODIS bands. Over the ocean the measured radiances are inverted into the aerosol optical depths at 470, 550, 659, 865, 1240, 1640 and $2130 \mathrm{~nm}$ and volume distribution (in the range of $0.08-5 \mu \mathrm{m}$ radius). In the inversion, it is assumed that the aerosol size distribution is bi-modal log-normal (Remer et al., 2005). Aerosol retrievals are produced at a resolution of nominally $10 \times 10 \mathrm{~km}^{2}$ at nadir. The MODIS aerosol algorithm uses the standard deviation of $0.55 \mu \mathrm{m}$ reflectances 
in groups of 3 by 3 pixels within a box (Martins et al., 2002) to define its cloud mask. If any group of 9 contiguous pixels has a standard deviation greater than 0.0025 , the center pixel is labeled as 'cloudy' and discarded. This test separates aerosol from most cloud types, but may fail at the centers of large, thick clouds and with cirrus, both of which can be spatially homogeneous. It may also erroneously identify inhomogeneous aerosol fields (e.g., dust) as clouds. In an effort to avoid both scenarios, additional spectral dependence filters are applied. There is an extensive body of literature documenting the validation of MODIS aerosol properties since the beginning of data collection by the MODIS-Terra instrument (e.g., Redemann et al., 2005, 2006, 2009a,c; Russell et al., 2007, Remer et al., 2005, 2008). Over oceans, MODIS AOD uncertainties have been shown to be about $\pm(0.03+0.05 \mathrm{AOD})$; over land retrieval uncertainties are generally $\pm(0.05+0.15 \mathrm{AOD})$ (Remer et al., 2005, Levy et al., 2010; Kleidman et al., 2011).

\subsection{CALIOP AOD derived from aerosol extinction profiles}

Within the A-Train, the CALIPSO satellite carries an elastic backscatter lidar (CALIOP), a three-channel imaging infrared radiometer (IIR) and a wide-field camera (WFC). The key instrument for this work is CALIOP, a two-wavelength (532 and $1064 \mathrm{~nm}$ ), polarization-sensitive (at $532 \mathrm{~nm}$ ) lidar that makes continuous profile measurements from the Earth's surface up to an altitude of $40-\mathrm{km}$. In the planetary boundary layer (PBL) and in the free troposphere up to an altitude of $8.2 \mathrm{~km}, 532 \mathrm{~nm}$ measurements are recorded at vertical and horizontal resolutions of $30 \mathrm{~m}$ and $333 \mathrm{~m}$, respectively. While boundary layer clouds are readily detected in the full resolution data, the single-shot signal-to-noise ratio (SNR) of the CALIOP profile data is too low to reliably retrieve aerosol spatial and optical properties (Hunt et al., 2009; Winker et al., 2009). Version 2 of the CALIOP level-2 data products reported aerosol spatial properties (in the layer product files) at a horizontal resolution of $5 \mathrm{~km}$, and range-resolved aerosol optical properties (in the profile product files) at a horizontal resolution of $40 \mathrm{~km}$. The new version 3 data products now report aerosol optical properties at the same 5-km horizontal resolution used for the spatial properties. However, the same optical properties retrieval strategy is used in both versions 2 and 3 of the CALIOP data products (Young and Vaughan, 2009). This technique does not provide a direct measurement of AOD, but instead derives estimates of AOD by first assessing the geo-spatial location and optical characteristics of aerosol layers, and then selecting a "best-match" extinction-to-backscatter ratio (also known as the lidar ratio) from a look-up Table based on a compilation of in-situ observations and a cluster analysis of AERONET data (Omar et al., 2009).

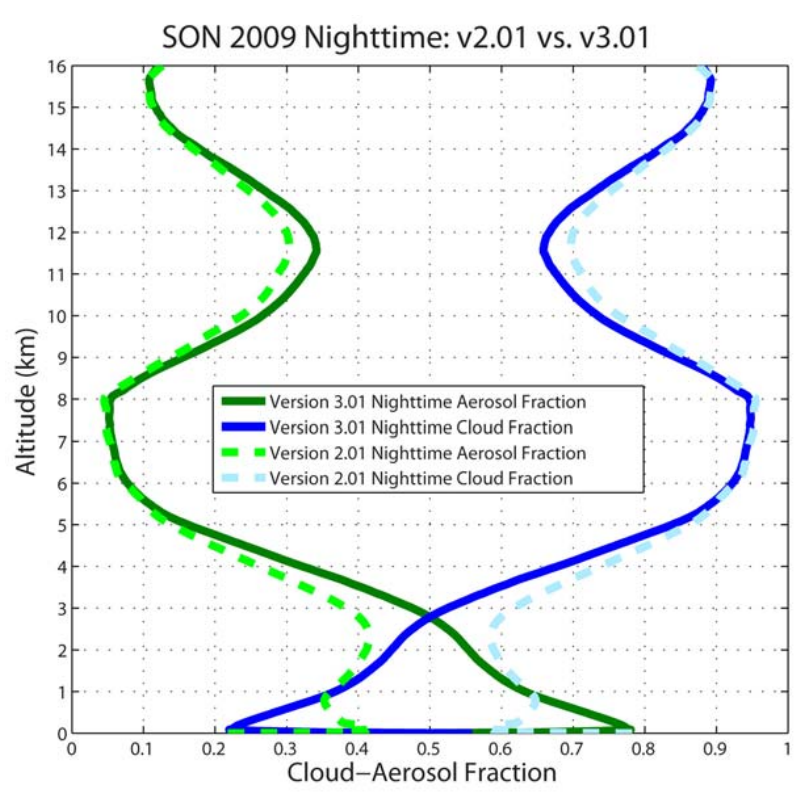

Fig. 1. Relative fraction of clouds and aerosols identified in the CALIOP V2 data products (dashed lines) versus the CALIOP V3 data products (solid lines) for daytime measurements during September, October, and November 2009. Below $\sim 4 \mathrm{~km}$, the V3 cloud fraction decreases sharply and continuously with respect to V2. Similarly, the V3 aerosol fraction shows the same dramatic increase with respect to the V2 aerosol fraction. The changes between $4 \mathrm{~km}$ and $2.5 \mathrm{~km}$ are due entirely to the repair of the V2 cloud clearing bug. Responsibility for the changes below $2.5 \mathrm{~km}$ is shared between the cloud clearing bug and the new aerosol base height identification scheme.

It should be noted that the CALIOP instrument was not primarily designed to provide aerosol extinction and hence AOD, but instead vertical profiles of aerosol attenuated backscatter (and depolarization), from which aerosol backscatter and extinction can be derived using an inversion algorithm. As such, the derivation of AOD from integration of extinction profiles is subject to several limitations and uncertainties. Kacenelenbogen et al. (2011) provide a description of the most important potential uncertainties in CALIOP AOD on the basis of a detailed multi-sensor case study. These are: (i) CALIOP's low signal-to-noise ratio (SNR), which can lead to the misclassification and/or lack of aerosol layer identification, especially for daytime measurements and/or in optically thick layers which rapidly attenuate the backscatter signal; (ii) possible cloud contamination of CALIOP aerosol backscatter and extinction profiles; (iii) potentially erroneous assumptions of the aerosol extinction-tobackscatter ratio $\left(S_{\mathrm{a}}\right)$ used in CALIOP's extinction retrievals; and (iv) calibration coefficient biases in the CALIOP attenuated backscatter coefficient profiles.

In going from CALIOP V2 to V3, major code and algorithm modifications were implemented. They were intended to result in more accurate V3 estimates of layer spatial and 
optical properties and can be summarized as follows.

1. Daytime calibration procedures were improved, resulting in more reliable detection of cloud and aerosol layers and more accurate extinction retrievals (Powell et al., 2010).

2. Significant changes to the version 3 layer detection module included the elimination of a bug in the cloud clearing code and the incorporation of a new scheme for determining base heights for low-lying aerosol layers (Vaughan et al., 2010). As shown in Fig. 1, the more accurate identification of dense clouds embedded in boundary layer aerosols results in substantially higher fraction of layers being correctly classified as aerosol in the version 3 product. The direct consequence of this improved cloud-aerosol discrimination is an improved accuracy and overall increase in the CALIOP V3 column AOD estimates, as demonstrated by Fig. 3a in Vaughan et al. (2010).

3. The probability distribution functions (PDFs) used in the $\mathrm{V} 3$ cloud-aerosol discrimination algorithm now considers five different attributes of each layer, adding latitude and depolarization ratio to the attributes considered in V2 (altitude, $532 \mathrm{~nm}$ backscatter intensity, and the ratio of integrated attenuated backscatters at $1064 \mathrm{~nm}$ and $532 \mathrm{~nm}$ ). Incorporating the 5D-PDFs has been especially effective in improving the ability to correctly classify very dense aerosol layers (Liu et al., 2010).

4. Cloud thermodynamic phase is now determined using an entirely new algorithm (Hu et al., 2009).

In addition, the V3 products also contain new diagnostics, quality assurance parameters and uncertainty estimates that were not available in prior releases (e.g., extinction QC flags, cloud and aerosol feature fraction, atmospheric volume description, column optical depths, ice water content, particulate depolarization ratio profile and associated uncertainties). These algorithm improvements influenced the CALIPSO project's decision to upgrade the maturity level of the optical depth data from a "beta" product in V2 to a "provisional" product in V3, the former not considered suitable for use in scientific publication. Nonetheless, the V2 data were used extensively in several published studies (e.g., Peyridieu et al., 2010; Jones and Christopher, 2010), partly motivating the quantitative comparisons presented in this paper.

\subsection{Data collocation}

As pointed out previously, the CALIOP V2 retrievals are based on CALIOP extinction profiles at a horizontal resolution of $40 \mathrm{~km}$. CALIOP V3 extinction profiles (and by extension our AOD retrievals) have a horizontal resolution of $5 \mathrm{~km}$. Fig. 2 shows the basic strategy for collocating MODIS

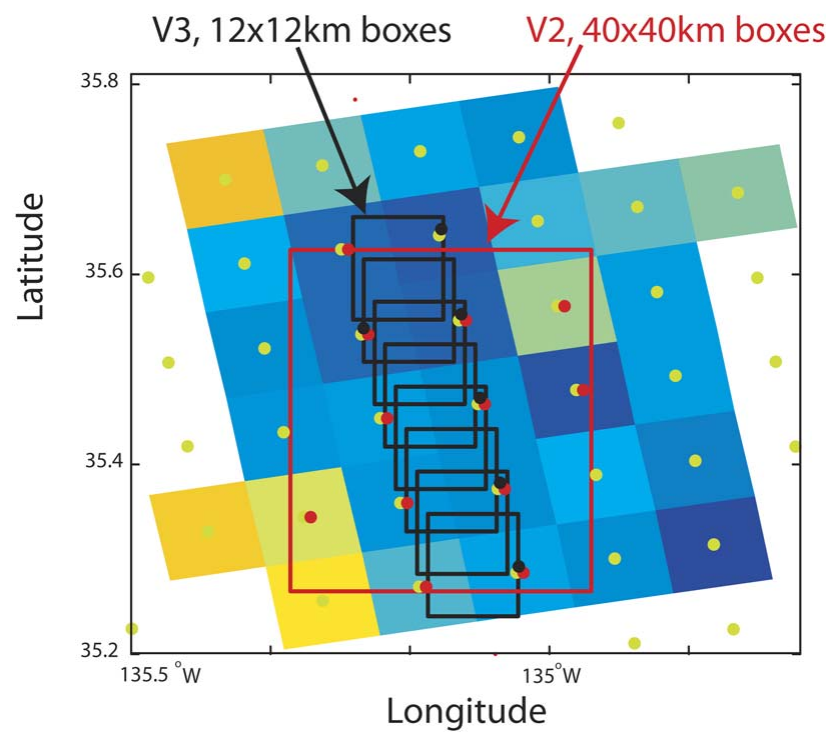

Fig. 2. Geometry for comparing MODIS AOD retrievals (solid boxes) to CALIOP V2 (40 km-average) and V3 (5 km-average) AOD retrievals. Black boxes around $\mathrm{V} 3$ retrieval locations represent the optimal sampling of the MODIS AOD retrievals (see Sect 2.3 for explanation of symbol colors).

AOD retrievals and CALIOP V2 and V3 derived AOD. For the comparison of CALIOP V2 AOD to MODIS AOD retrievals, we averaged all available, valid MODIS retrievals in a $40 \times 40 \mathrm{~km}^{2}$ grid box centered at the CALIOP V2 retrieval. As an example, this is illustrated by the two $40 \times 40 \mathrm{~km}^{2}$ boxes plotted in Fig. 2. MODIS AOD retrievals are shown by filled parallelograms, roughly measuring $10 \times 10 \mathrm{~km}^{2}$, as the CALIPSO ground track is near the nadir point of the MODIS scans. Along the CALIOP track, $40 \times 40 \mathrm{~km}^{2}$ boxes centered around the CALIOP V2 AOD retrieval center points are shown in red. Light green dots denote the center points of the MODIS retrieval boxes. The MODIS retrievals that were averaged for comparison to the two CALIOP V2 retrievals are denoted by red dots near the light green center dots. Black squares in Fig. 2 denote $12 \times 12 \mathrm{~km}^{2}$ boxes centered around the CALIOP V3 AOD retrieval center points. The $12 \times 12 \mathrm{~km}^{2}$ boxes were chosen because they present an optimum sampling of the MODIS retrievals. Smaller boxes $\left(\right.$ e.g., $\left.10 \times 10 \mathrm{~km}^{2}\right)$ often did not contain any center points of MODIS retrieval boxes; larger boxes (e.g., $15 \times 15 \mathrm{~km}^{2}$ ) would have resulted in undue spatial averaging of several MODIS retrieval boxes, as opposed to using just one closely collocated MODIS retrieval box. As an example, for October 1, 2007, using the $12 \times 12 \mathrm{~km}^{2}$ boxes resulted in an $84 \%$ probability of having exactly one MODIS retrieval in the box ( $16 \%$ had two retrievals); using $13 \times 13 \mathrm{~km}^{2}$ boxes resulted in a $74 \%$ probability of having exactly one MODIS retrieval in the box ( $24 \%$ had two retrievals, $2 \%$ had four retrievals); using $14 \times 14 \mathrm{~km}^{2}$ boxes resulted in a less than 

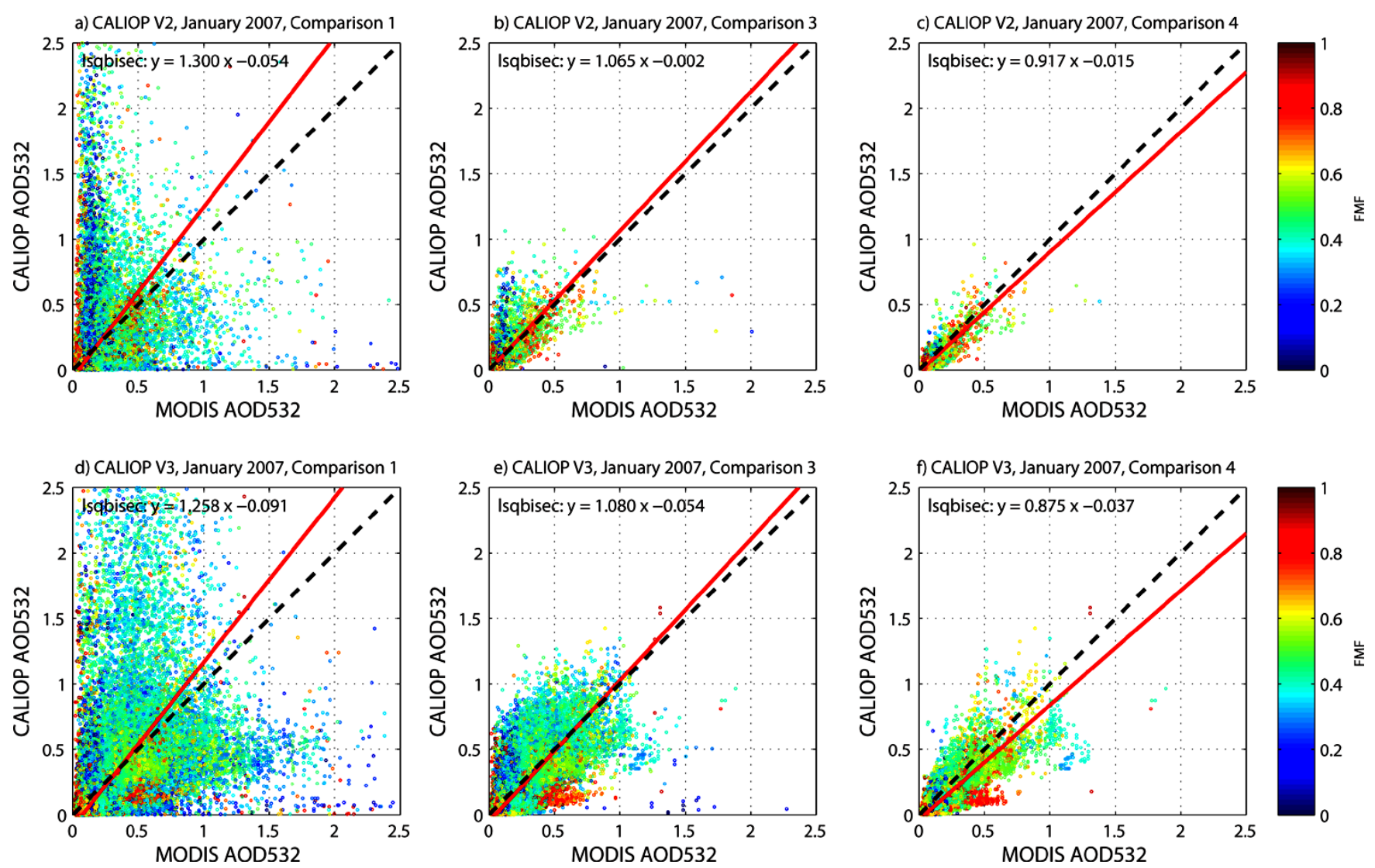

Fig. 3. (a) Comparison of all instantaneously collocated MODIS AOD retrievals for January of 2007 to AOD calculated from CALIOP V2 aerosol extinction profiles. (b) same as (a), but comparison screened with the methodology summarized as comparison \# 3 in Table 1 . (c) same as a), but comparison screened with the methodology summarized as comparison \# 4 in Table 1. (d), (e) and (f) are the same as (a), (b) and (c), respectively, but for CALIOP V3. Symbol color represents the MODIS derived fine mode fraction (FMF), i.e., the fraction of AOD that is due to the fine particle mode in the bi-modal fine-coarse mode retrieval.

$64 \%$ probability of having exactly one MODIS retrieval in the box ( $32 \%$ had two retrievals, more than $4 \%$ had four retrievals). At the same time, the average daily AOD changed by less than 0.001 (i.e., less than $1 \%$ ) between any one sampling option and the next, while RMS differences increased with box size. Hence, we conclude that $12 \times 12 \mathrm{~km}^{2}$ boxes centered at CALIOP V3 AOD retrievals provide an optimum sampling of MODIS retrievals for comparison of the two data sets.

\section{Results}

\subsection{One month comparison (January 2007) between MODIS AOD and CALIOP (V2 \& V3) AOD over ocean}

To illustrate the technical details of our comparison between MODIS and CALIOP AOD, this section discusses the comparison of MODIS and CALIOP AOD at $532 \mathrm{~nm}$ for January of 2007. As pointed out above, to calculate the CALIOP AOD at $532 \mathrm{~nm}$, we integrate the aerosol extinction profile contained in the scientific data segment (sds) "Extinction_Coefficient_532" with respect to altitude after replacing all fill values with a numerical value of zero. To facilitate the comparison with MODIS, we use a quadratic fit of $\log (\mathrm{AOD})$ versus $\log$ (wavelength) for the seven over-ocean MODIS spectral AOD (sds "Effective_Optical_Depth_Average_Ocean") and interpolate to a wavelength of $532 \mathrm{~nm}$. As described in section 2.3, we use different spatial matching between MODIS and CALIOP V2 on one hand, and between MODIS and CALIOP V3 on the other, because the CALIOP extinction profile data is presented at the higher horizontal resolution of $5 \mathrm{~km}$ in $\mathrm{V} 3$ along the CALIPSO ground track. This results in a comparison of CALIOP V2 data to MODIS retrievals in a $40 \times 40 \mathrm{~km}^{2}$ box, while the CALIOP V3 data are compared to spatially 
Table 1. Data attributes for different AOD comparisons.

\begin{tabular}{|c|c|c|}
\hline $\begin{array}{c}\text { Version } \rightarrow \\
\text { Comparison \# } \downarrow\end{array}$ & CALIOP V2 vs. MODIS & CALIOP V3 vs MODIS \\
\hline 1 & $\begin{array}{l}\text { CALIOP V2: all valid ext532 retrievals* } \\
(* \text { : from } 40 \mathrm{~km} \text { profile product) } \\
\text { MODIS: all valid AOD retrievals }\end{array}$ & $\begin{array}{l}\text { CALIOP V3: all valid ext532 retrievals } \$ \\
\text { ( } \$ \text { : from } 5 \mathrm{~km} \text { profile product) } \\
\text { MODIS: all valid AOD retrievals }\end{array}$ \\
\hline 2 & $\begin{array}{l}\text { CALIOP V2: } 0<\text { ext532<1.25* } \\
(* \text { from } 40 \mathrm{~km} \text { profile product) } \\
\text { MODIS: MODISQA }=1,2,3\end{array}$ & $\begin{array}{l}\text { CALIOP V3: } 0<\text { ext } 532<1.25 \ddagger \\
(\$: \text { from } 5 \mathrm{~km} \text { profile product) } \\
\text { MODIS: MODISQA }=1,2,3\end{array}$ \\
\hline 3 & $\begin{array}{l}\text { CALIOP V2: } 0<\text { ext532<1.25* \& } \\
\text { cloudOD }=0 * * \& \text { extQCflag }=0,1,2^{* *} \\
(*: \text { from } 40 \mathrm{~km} \text { profile product } \\
* * \text { from } 5 \mathrm{~km} \text { layer product }) \\
\text { MODIS: MODISQA }=1,2,3\end{array}$ & $\begin{array}{l}\text { CALIOP V3: } 0<\text { ext } 532<1.25 \ddagger \& \\
\text { cloudOD }=0 \ddagger \& \text { extQCflag }=0,1,2 \ddagger \\
\text { Delete profile if any extQCflag } \neq 0,1,2 \\
\text { ( } \ddagger \text { from } 5 \mathrm{~km} \text { profile product) } \\
\text { MODIS: MODISQA }=1,2,3\end{array}$ \\
\hline 4 & $\begin{array}{l}\text { CALIOP V2: } 0<\text { ext532<1.25* \& } \\
\text { cloudOD }=0 * * \& \text { extQCflag }=0,1,2 * * \\
(*: \text { from } 40 \mathrm{~km} \text { profile product } \\
* *: \text { from } 5 \mathrm{~km} \text { layer product) } \\
\text { MODIS: MODISQA }=1,2,3 \& \\
\text { FOC }<0.01\end{array}$ & $\begin{array}{l}\text { CALIOP V3: } 0<\text { ext } 532<1.25 \ddagger \& \\
\text { cloudOD }=0 \ddagger \& \text { extQCflag }=0,1,2 \ddagger \\
\text { Delete profile if any extQCflag } \neq 0,1,2 \\
(\ddagger: \text { from } 5 \mathrm{~km} \text { profile product) } \\
\text { MODIS: MODISQA }=1,2,3 \& \\
\text { FOC }<0.01\end{array}$ \\
\hline 5 & & 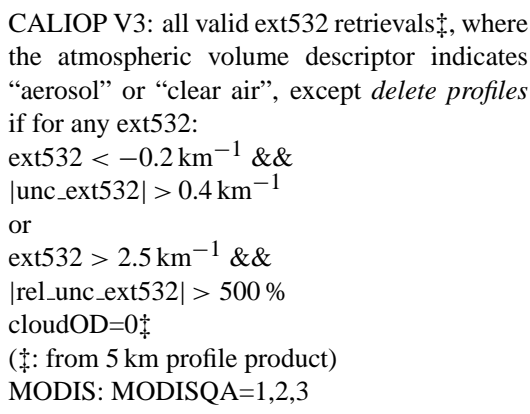 \\
\hline 6 & & $\begin{array}{l}\text { CALIOP V3: all valid col_AOD retrievals } \$ \text {, } \\
\text { except delete profiles if for any ext532: } \\
\text { rel_err }>100 \% \text {, where } \\
\text { rel_err }=\text { unc_col_AOD/col_AOD } \\
\text { ( } \$: \text { from } 5 \mathrm{~km} \text { profile product) } \\
\text { cloudOD }=0 \ddagger \\
\text { ( } \ddagger \text { from } 5 \mathrm{~km} \text { profile product) } \\
\text { MODIS: MODISQA }=1,2,3\end{array}$ \\
\hline
\end{tabular}

more closely collocated MODIS retrievals at the $12 \times 12 \mathrm{~km}^{2}$ scale. In a heterogeneous aerosol environment, the coarser spatial sampling for CALIOP V2 is likely to introduce some variability in the comparisons. Spatial variability of aerosol properties is discussed in more detail in the discussion section of our paper.

Figure 3 shows scatter plot comparisons between MODIS and CALIOP V2 in the first row (Fig. 3a-c) and between MODIS and CALIOP V3 (Fig. 3d-f) in the second row. The symbol color represents the MODIS derived fine mode fraction (FMF), i.e., the fraction of AOD that is due to the fine particle mode in the bi-modal fine-coarse mode retrieval. A large FMF indicates that the aerosol is dominated by fine mode particles with diameters less than one micrometer, often indicative of particles produced from anthropogenic sources. Small FMF points to a dominance of large particles, but often times indicates a possible cloud contamination as well. The solid red lines show the linear fits to the data using a model-2 regression method, i.e., the least-squares bisector method. In general, model-2 regressions are more appropriate when both data sets have measurement errors and when such errors are deemed to be of similar order of magnitude (e.g., Sokal and Rohlf, 1995). The fit parameters of this line are determined by calculating the slope of the line that bisects the minor angle between the regression of Y-on-X and X-onY. The fit line parameters along with monthly mean AOD from the two sensors, the mean and standard deviation of the difference between the two sensors, the number of available data points, the square of the linear correlation coefficient and the rms difference between the two data sets are given 
Table 2. MODIS vs. CALIOP AOD532, January 2007, over-ocean.

\begin{tabular}{lccccccc}
\hline & $\begin{array}{c}\text { MOD } \\
\text { mean }\end{array}$ & $\begin{array}{c}\text { CAL } \\
\text { mean }\end{array}$ & $\begin{array}{c}\text { MeanDiff./ } \\
\text { StdDiff. }\end{array}$ & No. & $R^{2}$ & $\begin{array}{c}\text { Slope/ } \\
\text { offset }\end{array}$ & $\begin{array}{c}\text { RMS } \\
\text { Abs/rel }\end{array}$ \\
\hline CALIOP Version 2 & & & & & & & \\
\hline Comparison \#1 & 0.180 & 0.180 & $0.0003 / 0.330$ & 36859 & 0.043 & $1.300 /-0.054$ & $0.330 / 183.2 \%$ \\
Comparison \#2 & 0.180 & 0.132 & $0.048 / 0.180$ & 36758 & 0.147 & $0.923 /-0.034$ & $0.186 / 103.6 \%$ \\
Comparison \#3 & 0.131 & 0.137 & $-0.007 / 0.124$ & 5750 & 0.342 & $1.065 /-0.002$ & $0.124 / 94.6 \%$ \\
Comparison \#4 & 0.147 & 0.120 & $0.027 / 0.082$ & 1883 & 0.655 & $0.917 /-0.015$ & $0.087 / 58.9 \%$ \\
\hline CALIOP Version 3 & & & & & & & \\
\hline Comparison \#1 & 0.170 & 0.123 & $0.047 / 0.189$ & 247976 & 0.247 & $1.258 /-0.091$ & $0.194 / 114.0 \%$ \\
Comparison \#2 & 0.170 & 0.111 & $0.059 / 0.127$ & 247951 & 0.390 & $0.859 /-0.035$ & $0.140 / 82.3 \%$ \\
Comparison \#3 & 0.147 & 0.105 & $0.042 / 0.093$ & 177741 & 0.474 & $1.080 /-0.054$ & $0.102 / 69.6 \%$ \\
Comparison \#4 & 0.147 & 0.092 & $0.055 / 0.085$ & 37740 & 0.635 & $0.875 /-0.037$ & $0.101 / 68.9 \%$ \\
Comparison \#5 & 0.147 & 0.112 & $0.036 / 0.130$ & 177743 & 0.382 & $1.408 /-0.096$ & $0.135 / 91.9 \%$ \\
Comparison \#6 & 0.152 & 0.109 & $0.043 / 0.124$ & 176378 & 0.375 & $1.091 /-0.057$ & $0.131 / 86.4 \%$ \\
\hline
\end{tabular}

in Table 2. Figure 3a and d show comparisons for all available collocated MODIS and CALIOP AOD retrievals in the month of January, i.e., 36859 for CALIOP V2 and 247976 for CALIOP V3. These numbers essentially reflect the 8 -fold increase in data density in going from CALIOP V2 to $\mathrm{V} 3$, although not all valid V2 $40 \mathrm{~km}$ retrievals necessarily contain eight valid V3 $5 \mathrm{~km}$ retrievals and not all valid V3 $5 \mathrm{~km}$ retrieval are collocated with valid V2 $40 \mathrm{~km}$ retrievals. In addition, changes in the retrieval algorithm, most notably with respect to cloud clearing, would result in differences between the two data sets. Comparing the correlations of CALIOP V2 and V3 with the MODIS data, we note a significantly better correlation for V3 ( $R^{2}$ of 0.25 as opposed to 0.04 for V2) and smaller rms differences ( 0.19 as opposed to 0.33 for V2). Mean differences from MODIS AOD, however, are smaller for V2 than for V3. We speculate that this result is caused by competing factors. The steps taken in between CALIOP V2 and V3 certainly reduced the cloud contamination, lowering the mean V3 AOD. At the same time other steps taken, for example the extension of extinction profiles all the way to the ground in low transmission cases, likely increased the mean V3 AOD. The better agreement between CALIOP V2 AOD and MODIS is hence serendipitous.

To investigate if an application of the various quality criteria published in the MODIS and CALIOP data sets result in better agreement between the two AOD data sets, we carried out several tests, which successively increased the complexity of the data screening process. Table 1 provides the details of the various comparisons. Starting with the comparisons of all data (comparison \#1), we added the following restrictions, requiring:

1. MODIS AOD data to have an aerosol quality flag (Quality_Assurance_Ocean) of 1 (marginal), 2 (good), or 3 (very good) (comparisons \# 2-6 in Table 1);
2. CALIOP extinction retrievals to fall within the "valid range" (identified in the CALIPSO data products cata$\log$ as 0 to $1.25 \mathrm{~km}^{-1}$ ) (comparisons \# 2-4 in Table 1);

3. CALIOP extinction retrievals to have quality flags of 0 , 1 or 2 and to eliminate profiles for which any extinction retrievals do not have said quality flags (comparisons \# 3-5 in Table 1);

4. CALIOP extinction profiles to have collocated cloud optical depth retrievals equal to zero (comparisons \# 36 in Table 1);

5. MODIS cloud fractions (as determined by the aerosol algorithm) to be below $1 \%$ (comparison \# 4 in Table 1);

6. CALIOP extinction retrievals to have uncertainties (i.e., as calculated according to Young et al., 2008) less than $200 \%$ when extinction is below negative $0.2 \mathrm{~km}^{-1}$, or less than $500 \%$ when extinction is greater than $2.5 \mathrm{~km}^{-1}$ and to eliminate profiles for which any extinction retrievals do not have said extinction coefficients and uncertainty limits (as described in comparison \# 5 in Table 1);

7. CALIOP relative AOD uncertainty calculated from the extinction uncertainties to be below $100 \%$ (comparison \# 6 in Table 1).

We show comparison \#1 to illustrate the impact of neglecting the quality flags in MODIS and CALIOP retrievals. As stated in the peer-reviewed literature before (Russell et al., 2007, Remer et al., 2005, 2008), MODIS AOD retrievals with QA confidence flag less than 3 over land and less than 1 over ocean are not recommended for quantitative scientific use. Including only MODIS data with QA confidence flags recommended for quantitative scientific use increases our confidence in judging the utility of the various filtering methods of the CALIOP extinction retrievals in comparisons \#2-\#6. 
Uncertainties in the CALIOP particulate volume extinction coefficient are computed from combined systematic and random errors in the particulate extinction-to-backscatter ratio and the particulate volume backscatter coefficient (see Eq. (16) of http://eosweb.larc.nasa.gov/PRODOCS/calipso/ pdf/CALIOP_Version3_Extinction_Error_Analysis.pdf). Ignoring multiple scattering concerns in Version 3, the three main sources of uncertainties are the signal-to-noise ratio (depends on the backscatter intensity, the lighting conditions (i.e., day vs. night), and the amount of horizontal averaging applied to the initial attenuated backscatter profiles), the calibration coefficient, and the accuracy of the lidar ratio specified for use in the solution within each detected aerosol layer. Except for constrained solutions, where a lidar ratio estimate can be obtained directly from the attenuated backscatter data, lidar ratio uncertainties are almost always the dominant contributor to optical depth uncertainties, and the relative error in the layer optical depth will always be at least as large as the relative error in the lidar ratio for a given layer.

Figure $3 \mathrm{~b}$ and e show the same comparisons as Fig. 3a and $\mathrm{d}$, after the application of the data quality criteria summarized as comparison \#3 in Table 1. First, we restrict the comparison to MODIS data with an aerosol quality flag (Quality_Assurance_Ocean) of 1 (marginal), 2 (good), or 3 (very good), all designated as appropriate for quantitative use (Russell et al., 2007; Remer et al., 2008; Bréon et al., 2011). Second, we only use extinction retrievals that were in the documented valid range of 0 to $1.25 \mathrm{~km}^{-1}$. Third, we only use extinction profiles for which all extinction retrievals have a quality flag of 0,1 or 2 . The CALIOP extinction quality flags describe the final state of the Hybrid Extinction Retrieval Algorithm (HERA; see Young and Vaughan, 2009). The most reliable retrievals are those for which a direct measure of layer attenuation can be obtained by comparing the signal magnitudes in clear air regions immediately above and below a layer. In these cases, for which HERA reports an extinction quality flag of 1 , the measured attenuation provides a constraint for the solution of the lidar equation and thus a direct estimate of the layer lidar ratio can be retrieved. When this kind of constrained retrieval is not possible (as is always the case with surface-attached aerosol layers), HERA derives optical depths using an assumed value of the lidar ratio. Retrievals of this type are assigned an extinction quality flag of 0 . When the assumed value of the lidar ratio is too large, the extinction solution will begin to diverge toward positive infinity, and therefore to obtain a successful solution the lidar ratio must be reduced. An extinction quality flag of 2 identifies these situations, which occur very rarely in the analysis of aerosol layers. Other extinction quality flag values indicate algorithm termination conditions that are considered unreliable for the purposes of the current study. Fourth, we only use comparisons for which the CALIOP data indicates a cloud optical depth of zero.

This combination of quality criteria is summarized as comparison \# 3 in Table 1. V3 aerosol profile data files contain an sds entitled "Column_Optical_Depth_Cloud_532", which we used for the second step described above. The CALIOP V2 aerosol profile data, however, contained no analogous data field. We therefore used the V2 cloud layer data (at $5 \mathrm{~km}$ resolution) and only allowed data that showed no cloud layers as indicated by the sds "Number_Layers_Found". Because the V2 profile data is reported at a horizontal resolution of $40 \mathrm{~km}$, yet the cloud layer products are reported at a resolution of $5 \mathrm{~km}$, we only used V2 $40 \mathrm{~km}$ aerosol extinction profile data for which all eight $5 \mathrm{~km}$ sub-segments showed no cloud layers present. Effectively, this represents a very stringent cloud screening, as no V2 extinction data were used in our analysis if even a single $5 \mathrm{~km}$ sub-segment was reported to contain a cloud. Consequently, the application of the three quality criteria (MODISQA $=1-3$, CALIOPcloudOD $=0$, extQCflag $=0,1,2$ ) has a much more dramatic impact on the $\mathrm{V} 2$ comparisons than on the $\mathrm{V} 3$ comparisons to MODIS. For V2, only about $15 \%$ of the original data shown in Fig. 3a are still present in Fig. 3b. For V3, more than $72 \%$ of the data survive the application of these quality criteria. There is significant improvement after application of the quality criteria for both CALIOP V2 and V3, especially with respect to rms differences.

As an additional restriction to even more cloud-free conditions, Fig. $3 \mathrm{c}$ and $\mathrm{f}$ show the comparisons between MODIS and CALIOP for cloud fractions of less than $1 \%$ as defined by the MODIS aerosol product (Cloud_Fraction_Ocean). The statistical parameters for these comparisons are given as comparison \# 4 in Table 2 . Both V2 and V3 show larger correlation coefficients (both $R^{2}$ greater than 0.5 ). It should be noted, however, that there is 20 times more data in CALIOP V3 $(N=37740)$ than in CALIOP V2 $(N=1883)$ that remains after application of the four quality criteria and restriction to cloud fractions less than $1 \%$. In terms of absolute numbers, the remaining V2 retrievals represent about $5 \%$ of all valid V2 retrievals, while the remaining V3 retrievals represent more than $15 \%$ of all valid V3 retrievals.

We tested several other methodologies for combining the various restrictions described in the previous paragraphs. Two such combinations are described as comparison \# 5 and \# 6 in Table 1. Comparison \# 5 tests the usefulness of the CALIOP extinction uncertainties, and comparison \# 6 tests the usefulness of the published uncertainty in the CALIOP column AOD. In comparison \# 5, we restrict our AOD comparison to use only CALIOP extinction retrievals whose uncertainties are below $200 \%$ at the low (negative) end of the extinction spectrum and below $500 \%$ at the high end of the extinction spectrum. Examining the pre-filtered and postfiltered distributions of aerosol subtypes shows that the uncertainty filter parameters chosen for this study do not preferentially include or exclude any of the CALIPSO aerosol subtypes from the final data set. We allowed negative values in the extinction, because some range of small negative values is plausible based on the retrieval technique and simple statistical scatter of solutions around the correct retrieval. Table 2 

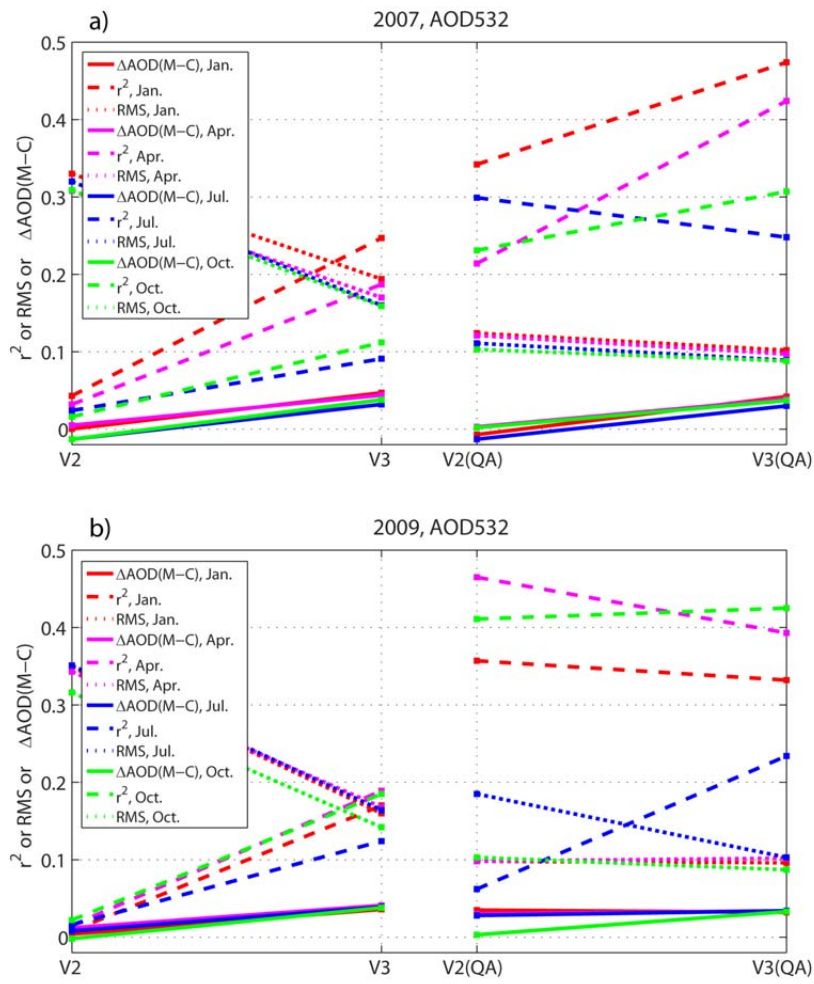

Fig. 4. (a) Left - Comparison of agreement between MODIS AOD and CALIOP V2 and V3 AOD, respectively, in terms of difference in mean AOD, square of the linear correlation coefficient, and rms difference, for four months in 2007. Right - same as left, but for data after application of comparison \# 3 in Table 1. (b) same as (a), but for four months in 2009.

shows that an application of comparison \# 5 and \# 6 to the January 2007 data results in less good correlation between the two data sets. Similar tests with different ranges of allowable CALIOP extinction values (not shown here) also provided no improvement in correlation when compared to the methodology of comparison \# 3. Therefore, we summarize the best methodology for comparing MODIS and CALIOP V3 AOD to consist of the following 4 steps:

1. use MODIS aerosol quality flag (Quality_Assurance_Ocean) of 1-3;

2. use only CALIOP extinction retrievals that fall within the "valid range" of 0 to $1.25 \mathrm{~km}^{-1}$;

3. require CALIOP extinction profiles to have collocated cloud Optical depth retrievals equal to zero; and

4. eliminate CALIOP profiles for which any extinction retrievals have quality flags different from 0,1 or 2 .

As we will see in Sect. 3.2, applying these quality criteria eliminates only $20-30 \%$ of all collocated cases and results in the best correlation between the two AOD data sets.

\subsection{Eight months of comparisons (Jan, Apr, Jul, Oct 2007 and 2009) between MODIS AOD and CALIOP (V2 \& V3) AOD over land and ocean}

In this section we extend the results shown in Sect. 3.1 to eight months of data: Jan, Apr, Jul and Oct of 2007 and 2009. Considering several months within one year will allow us to study whether certain aerosol types in certain geographical regions contribute differently to the global MODIS-CALIOP AOD differences. By considering two years of data (2007 and 2009) we are able to assess potential sensor calibration or performance changes.

Figure 4a shows the comparison of MODIS to CALIOP V2 and V3 AOD (532 nm) for four months in 2007 in terms of three parameters: (1) $\triangle$ AOD (M-C), the global monthly mean difference in AOD (MODIS-CALIOP), (2) the square of the linear correlation coefficient $\left(R^{2}\right)$, and (3) the RMS difference between MODIS and the respective CALIOP retrievals. The left hand side of Fig. 4a shows these parameters for all retrievals in CALIOP V2 and V3, while the right hand side only shows the comparison using the quality criteria summarized as comparison \# 3 in Table 1. Consequently, the numerical results shown in Fig. 4a can be found in Tables 2-5 and the results in Fig. $4 \mathrm{~b}$ are given in Tables 6-9 (in the rows entitled "comparison \#3"). Hereafter, we will refer to these comparisons as V2QA and V3QA, respectively. Figure $4 \mathrm{~b}$ shows the same data for four months in 2009.

In going from V2 to V3 for all data (left hand side in Figures $4 \mathrm{a}$ and $4 \mathrm{~b}$, as well as comparison \# 1 in Tables 2-9), the analysis is consistent between different months and even between 2007 and 2009. The mean optical depth differences between MODIS and CALIOP increase in going from V2 to V3. However, the correlation coefficients (dashed lines) increase from V2 to V3, and RMS differences (dotted lines) decrease from values greater than 0.3 to values between 0.15 and 0.2 .

The comparisons for the quality assured data sets (right hand sides of Figure $4 \mathrm{a}$ and $\mathrm{b}$ as well as comparison \# 3 in Tables 2-9) are less straight forward. In 2007 (Fig. 4a), the mean differences from MODIS increase between V2QA and V3QA, while in 2009 the differences to MODIS for three of the four months essentially stay the same. The correlation with MODIS data increases between V2QA and V3QA for January 2007, April 2007, October 2007 and July 2009. For, January and October 2009 it is essentially unchanged between V2QA and V3QA, and for July 2007 and April 2009, the correlation with MODIS data decreases between V2QA and V3QA. However, as discussed in Sect. 3.1, the quality-assured V2QA data only represents a small fraction of the original V2 data and the four quality criteria effectively represent a strong initial cloud filter, making the comparison between V2QA and V3QA somewhat misleading. Comparison 4 in Tables 2-9 illustrates that after application of the criterion that MODIS cloud fractions as determined by the aerosol algorithm have to be below $1 \%$, the 
Table 3. MODIS vs. CALIOP AOD532, April 2007, over-ocean.

\begin{tabular}{lccccccc}
\hline & $\begin{array}{c}\text { MOD } \\
\text { mean }\end{array}$ & $\begin{array}{c}\text { CAL } \\
\text { mean }\end{array}$ & $\begin{array}{c}\text { MeanDiff./ } \\
\text { StdDiff. }\end{array}$ & No. & $R^{2}$ & $\begin{array}{c}\text { Slope/ } \\
\text { offset }\end{array}$ & $\begin{array}{c}\text { RMS } \\
\text { Abs/rel }\end{array}$ \\
\hline CALIOP Version 2 & & & & & & & \\
\hline Comparison \#1 & 0.169 & 0.164 & $0.005 / 0.308$ & 34024 & 0.032 & $1.356 /-0.065$ & $0.308 / 182.3 \%$ \\
Comparison \#2 & 0.169 & 0.123 & $0.046 / 0.160$ & 33943 & 0.095 & $1.002 /-0.046$ & $0.166 / 98.5 \%$ \\
Comparison \#3 & 0.126 & 0.124 & $0.003 / 0.121$ & 3426 & 0.214 & $1.164 /-0.023$ & $0.121 / 95.7 \%$ \\
Comparison \#4 & 0.141 & 0.112 & $0.029 / 0.079$ & 805 & 0.632 & $1.018 /-0.032$ & $0.084 / 59.7 \%$ \\
\hline CALIOP Version 3 & & & & & & & \\
\hline Comparison \#1 & 0.156 & 0.112 & $0.044 / 0.164$ & 221680 & 0.187 & $1.322 /-0.094$ & $0.170 / 109.1 \%$ \\
Comparison \#2 & 0.156 & 0.104 & $0.052 / 0.113$ & 221650 & 0.295 & $0.964 /-0.046$ & $0.124 / 79.5 \%$ \\
Comparison \#3 & 0.140 & 0.101 & $0.039 / 0.089$ & 158534 & 0.424 & $1.090 /-0.051$ & $0.097 / 69.6 \%$ \\
Comparison \#4 & 0.144 & 0.099 & $0.046 / 0.083$ & 32047 & 0.586 & $1.010 /-0.047$ & $0.095 / 65.9 \%$ \\
\hline
\end{tabular}

Table 4. MODIS vs. CALIOP AOD532, July 2007, over-ocean.

\begin{tabular}{lccccccc}
\hline & $\begin{array}{c}\text { MOD } \\
\text { mean }\end{array}$ & $\begin{array}{c}\text { CAL } \\
\text { mean }\end{array}$ & $\begin{array}{c}\text { MeanDiff./ } \\
\text { StdDiff. }\end{array}$ & No. & $R^{2}$ & $\begin{array}{c}\text { Slope/ } \\
\text { offset }\end{array}$ & $\begin{array}{c}\text { RMS } \\
\text { Abs/rel }\end{array}$ \\
\hline CALIOP Version 2 & & & & & & & \\
\hline Comparison \#1 & 0.149 & 0.162 & $-0.013 / 0.320$ & 23121 & 0.024 & $1.356 /-0.040$ & $0.320 / 215.4 \%$ \\
Comparison \#2 & 0.149 & 0.115 & $0.034 / 0.144$ & 23051 & 0.148 & $1.015 /-0.036$ & $0.147 / 99.2 \%$ \\
Comparison \#3 & 0.105 & 0.118 & $-0.013 / 0.111$ & 3245 & 0.299 & $1.064 / 0.006$ & $0.111 / 106.1 \%$ \\
Comparison \#4 & 0.100 & 0.106 & $-0.006 / 0.077$ & 1035 & 0.571 & $1.123 /-0.006$ & $0.077 / 77.4 \%$ \\
\hline CALIOP Version 3 & & & & & & & \\
\hline Comparison \#1 & 0.131 & 0.099 & $0.032 / 0.157$ & 156614 & 0.091 & $1.272 /-0.067$ & $0.160 / 122.4 \%$ \\
Comparison \#2 & 0.131 & 0.091 & $0.040 / 0.100$ & 156592 & 0.221 & $0.938 /-0.032$ & $0.108 / 82.2 \%$ \\
Comparison \#3 & 0.117 & 0.087 & $0.030 / 0.084$ & 121252 & 0.248 & $0.997 /-0.030$ & $0.089 / 75.9 \%$ \\
Comparison \#4 & 0.100 & 0.069 & $0.031 / 0.082$ & 20392 & 0.316 & $0.829 /-0.014$ & $0.088 / 87.5 \%$ \\
\hline
\end{tabular}

difference between V2QA and V3QA in terms of correlation with MODIS data is negligible, with most RMS differences near 0.1 .

Because of the relatively better performance of the data screening methodology summarized as comparison \# 3 in Table 1 to all other methodologies, starting with Fig. 5, all MODIS versus CALIOP V3 AOD comparisons were screened according to that methodology. Figure 5 shows the difference between MODIS and V3QA data as histograms. The blue curves represent over-ocean data. Comparing all eight months in 2007 and 2009, we observe a consistent difference between MODIS and CALIOP V3QA of the order of $0.03-0.04$. The AOD difference is essentially normally distributed. In addition to the over-ocean data, we present the over-land comparisons (using MODIS sds "Corrected_Optical_Depth_Land") for each month as red distribution curves. We note the much broader distributions with mode values near -0.01 . The broader distributions are attributable to the larger uncertainties in MODIS over-land AOD retrievals, as well as differences in the aerosol type identified by the CALIOP aerosol classification scheme, the latter affecting the choice of lidar ratios in the CALIOP re- trieval. Uncertainties in CALIOP retrievals due to increased noise from surface scattering are secondary to the effects mentioned above.

\subsection{Geographical distribution of AOD differences between MODIS and CALIOP V3}

In this section we present results regarding the geographical distribution of the AOD differences between MODIS and CALIOP V3QA. Figure 6 shows the latitudinally averaged AOD differences for over-ocean retrievals (blue lines) and over-land retrievals (red lines). The thin lines represent 1degree averaged data, while the thick lines represent 5-degree averages. Figure 6a-d show the data for 2007, while Fig. 6e$\mathrm{h}$ show the data for 2009. As the thin lines in Fig. 6 indicate, the 1-degree data is considerably noisier over-land than over-ocean. This is due to both the decreased quality of the over-land MODIS retrievals, as well as the data sparseness in some latitude regions. Figure 7 shows the same comparisons but restricted to data with MODIS cloud fractions less than $1 \%$ (Cloud_Fraction_Ocean/Land $<0.01$, comparison \# 4 in Table 1). Focusing on the over-ocean comparisons, there are 
Table 5. MODIS vs. CALIOP AOD532, October 2007, over-ocean.

\begin{tabular}{lccccccc}
\hline & $\begin{array}{c}\text { MOD } \\
\text { mean }\end{array}$ & $\begin{array}{c}\text { CAL } \\
\text { mean }\end{array}$ & $\begin{array}{c}\text { MeanDiff./ } \\
\text { StdDiff. }\end{array}$ & No. & $R^{2}$ & $\begin{array}{c}\text { Slope/ } \\
\text { offset }\end{array}$ & $\begin{array}{c}\text { RMS } \\
\text { Abs/rel }\end{array}$ \\
\hline CALIOP Version 2 & & & & & & & \\
\hline Comparison \#1 & 0.149 & 0.161 & $-0.013 / 0.309$ & 35345 & 0.016 & $1.387 /-0.045$ & $0.309 / 208.0 \%$ \\
Comparison \#2 & 0.149 & 0.114 & $0.035 / 0.141$ & 35275 & 0.058 & $1.109 /-0.051$ & $0.145 / 97.6 \%$ \\
Comparison \#3 & 0.115 & 0.113 & $0.002 / 0.103$ & 5814 & 0.231 & $1.211 /-0.026$ & $0.103 / 89.8 \%$ \\
Comparison \#4 & 0.123 & 0.094 & $0.029 / 0.064$ & 2129 & 0.577 & $1.000 /-0.029$ & $0.070 / 57.2 \%$ \\
\hline CALIOP Version 3 & & & & & & & \\
\hline Comparison \#1 & 0.141 & 0.102 & $0.038 / 0.154$ & 243572 & 0.112 & $1.391 /-0.093$ & $0.159 / 112.7 \%$ \\
Comparison \#2 & 0.141 & 0.094 & $0.047 / 0.098$ & 243539 & 0.212 & $1.029 /-0.051$ & $0.109 / 77.1 \%$ \\
Comparison \#3 & 0.129 & 0.092 & $0.037 / 0.080$ & 183311 & 0.307 & $1.142 /-0.056$ & $0.088 / 68.2 \%$ \\
Comparison \#4 & 0.124 & 0.079 & $0.046 / 0.068$ & 39198 & 0.487 & $0.987 /-0.044$ & $0.082 / 65.8 \%$ \\
\hline
\end{tabular}

Table 6. MODIS vs. CALIOP AOD532, January 2009, over-ocean.

\begin{tabular}{lccccccc}
\hline & $\begin{array}{c}\text { MOD } \\
\text { mean }\end{array}$ & $\begin{array}{c}\text { CAL } \\
\text { mean }\end{array}$ & $\begin{array}{c}\text { MeanDiff./ } \\
\text { StdDiff. }\end{array}$ & No. & $R^{2}$ & $\begin{array}{c}\text { Slope/ } \\
\text { offset }\end{array}$ & $\begin{array}{c}\text { RMS } \\
\text { Abs/rel }\end{array}$ \\
\hline CALIOP Version 2 & & & & & & & \\
\hline Comparison \#1 & 0.153 & 0.149 & $0.004 / 0.349$ & 37824 & 0.008 & $1.257 /-0.043$ & $0.349 / 228.3 \%$ \\
Comparison \#2 & 0.153 & 0.092 & $0.061 / 0.130$ & 37715 & 0.102 & $0.931 /-0.051$ & $0.144 / 94.2 \%$ \\
Comparison \#3 & 0.122 & 0.087 & $0.035 / 0.091$ & 4689 & 0.357 & $0.834 /-0.015$ & $0.098 / 80.1 \%$ \\
Comparison \#4 & 0.128 & 0.082 & $0.046 / 0.074$ & 1632 & 0.564 & $0.725 /-0.011$ & $0.087 / 68.3 \%$ \\
\hline CALIOP Version 3 & & & & & & & \\
\hline Comparison \#1 & 0.144 & 0.108 & $0.036 / 0.155$ & 244148 & 0.170 & $1.365 /-0.088$ & $0.160 / 110.6 \%$ \\
Comparison \#2 & 0.144 & 0.099 & $0.045 / 0.104$ & 244136 & 0.278 & $0.994 /-0.044$ & $0.113 / 78.3 \%$ \\
Comparison \#3 & 0.130 & 0.097 & $0.032 / 0.091$ & 180852 & 0.332 & $1.093 /-0.045$ & $0.096 / 74.1 \%$ \\
Comparison \#4 & 0.122 & 0.077 & $0.044 / 0.074$ & 35324 & 0.484 & $0.895 /-0.032$ & $0.087 / 71.1 \%$ \\
\hline
\end{tabular}

some remarkably similar features between 2007 and 2009. For example, there is a consistent difference in April of near 0.1 in the Northern Hemisphere. In July, centered near $5^{\circ} \mathrm{S}$, there is a similar, though more localized, increase in the difference between MODIS and CALIOP V3QA. Interestingly, both of these features are also present in the cloud-screened data in Fig. 7, making cloud contamination rather unlikely as a possible cause of the discrepancy.

Figures 8 and 9 show the global distribution of the number of instantaneously collocated comparisons between MODIS and CALIOP V3QA in a $5 \times 5$ degree box for each month in the left hand plots ( $a-d$ of each figure) and the AOD difference in the right hand plots. Several interesting features are observable. The aforementioned AOD difference in April in the Northern Hemisphere seems to be due mostly to outflow from Asia. The AOD difference feature in the Southern hemisphere in July seems to be due almost exclusively to transport of biomass burning aerosols off of the African subcontinent into the Atlantic Basin (Matichuk et al., 2008). More in-depth studies are required to determine the most likely cause(s) for these disagreements. For the East Asia case in April, initial investigations might focus on possible failure by CALIPSO to detect diffuse dust layers in the middle troposphere and/or cloud contamination of the MODIS signals (Huang et al., 2011). Closer examination of the cloud-aerosol discrimination algorithms for both sensors would likely be a profitable strategy for assessing the West Africa case in July. On the other hand, these plots side by side also illustrate that most emphasis should be placed on locations where the vast majority of instantaneously collocated observations are made. This area is generally confined to the region 40 degrees to the North and South of the equator, with the notable exception of the region between $10^{\circ} \mathrm{N}$ and $40^{\circ} \mathrm{N}$ in July, where the CALIOP retrievals are inside the MODIS glint region and no coincident, collocated observations can be made by the two sensors.

We note further that the collocated over-land comparisons, while much less frequent, generally provide a consistent picture with the adjacent regional over-ocean comparisons. For example, the large positive difference between MODIS and CALIOP V3QA along the West-African coast near $5^{\circ} \mathrm{S}$ in July 2009 is also found in the inland retrievals. 
Table 7. MODIS vs. CALIOP AOD532, April 2009, over-ocean.

\begin{tabular}{lccccccc}
\hline & $\begin{array}{c}\text { MOD } \\
\text { mean }\end{array}$ & $\begin{array}{c}\text { CAL } \\
\text { mean }\end{array}$ & $\begin{array}{c}\text { MeanDiff./ } \\
\text { StdDiff. }\end{array}$ & No. & $R^{2}$ & $\begin{array}{c}\text { Slope/ } \\
\text { offset }\end{array}$ & $\begin{array}{c}\text { RMS } \\
\text { Abs/rel }\end{array}$ \\
\hline CALIOP Version 2 & & & & & & & \\
\hline Comparison \#1 & 0.165 & 0.153 & $0.012 / 0.343$ & 38617 & 0.015 & $1.265 /-0.056$ & $0.343 / 207.8 \%$ \\
Comparison \#2 & 0.165 & 0.100 & $0.065 / 0.145$ & 38543 & 0.129 & $0.895 /-0.047$ & $0.159 / 96.4 \%$ \\
Comparison \#3 & 0.141 & 0.111 & $0.030 / 0.094$ & 4835 & 0.465 & $1.025 /-0.034$ & $0.098 / 69.9 \%$ \\
Comparison \#4 & 0.156 & 0.118 & $0.038 / 0.083$ & 2169 & 0.575 & $1.079 /-0.050$ & $0.092 / 58.6 \%$ \\
\hline CALIOP Version 3 & & & & & & & \\
\hline Comparison \#1 & 0.154 & 0.113 & $0.041 / 0.163$ & 246057 & 0.189 & $1.322 /-0.091$ & $0.168 / 109.1 \%$ \\
Comparison \#2 & 0.154 & 0.105 & $0.050 / 0.116$ & 246049 & 0.288 & $1.008 /-0.051$ & $0.126 / 81.6 \%$ \\
Comparison \#3 & 0.138 & 0.104 & $0.034 / 0.096$ & 179128 & 0.393 & $1.173 /-0.058$ & $0.102 / 73.7 \%$ \\
Comparison \#4 & 0.147 & 0.107 & $0.040 / 0.092$ & 36121 & 0.568 & $1.161 /-0.063$ & $0.100 / 67.9 \%$ \\
\hline
\end{tabular}

Table 8. MODIS vs. CALIOP AOD532, July 2009, over-ocean.

\begin{tabular}{lccccccc}
\hline & $\begin{array}{c}\text { MOD } \\
\text { mean }\end{array}$ & $\begin{array}{c}\text { CAL } \\
\text { mean }\end{array}$ & $\begin{array}{c}\text { MeanDiff./ } \\
\text { StdDiff. }\end{array}$ & No. & $R^{2}$ & $\begin{array}{c}\text { Slope/ } \\
\text { offset }\end{array}$ & $\begin{array}{c}\text { RMS } \\
\text { Abs/rel }\end{array}$ \\
\hline CALIOP Version 2 & & & & & & & \\
\hline Comparison \#1 & 0.168 & 0.159 & $0.008 / 0.351$ & 27077 & 0.016 & $1.211 /-0.044$ & $0.351 / 209.6 \%$ \\
Comparison \#2 & 0.168 & 0.110 & $0.057 / 0.179$ & 27026 & 0.082 & $0.903 /-0.041$ & $0.188 / 112.1 \%$ \\
Comparison \#3 & 0.124 & 0.096 & $0.028 / 0.183$ & 3959 & 0.062 & $0.819 /-0.006$ & $0.185 / 149.7 \%$ \\
Comparison \#4 & 0.116 & 0.078 & $0.038 / 0.098$ & 1219 & 0.368 & $0.876 /-0.024$ & $0.105 / 91.0 \%$ \\
\hline CALIOP Version 3 & & & & & & & \\
\hline Comparison \#1 & 0.142 & 0.103 & $0.039 / 0.159$ & 167115 & 0.124 & $1.157 /-0.061$ & $0.164 / 115.5 \%$ \\
Comparison \#2 & 0.142 & 0.097 & $0.045 / 0.116$ & 167105 & 0.224 & $0.873 /-0.027$ & $0.125 / 88.0 \%$ \\
Comparison \#3 & 0.127 & 0.093 & $0.034 / 0.097$ & 131583 & 0.234 & $0.973 /-0.031$ & $0.103 / 80.8 \%$ \\
Comparison \#4 & 0.117 & 0.077 & $0.040 / 0.110$ & 22652 & 0.296 & $0.862 /-0.024$ & $0.117 / 99.9 \%$ \\
\hline
\end{tabular}

Table 9. MODIS vs. CALIOP AOD532, October 2009, over-ocean.

\begin{tabular}{lccccccc}
\hline & $\begin{array}{c}\text { MOD } \\
\text { mean }\end{array}$ & $\begin{array}{c}\text { CAL } \\
\text { mean }\end{array}$ & $\begin{array}{c}\text { MeanDiff./ } \\
\text { StdDiff. }\end{array}$ & No. & $R^{2}$ & $\begin{array}{c}\text { Slope/ } \\
\text { offset }\end{array}$ & $\begin{array}{c}\text { RMS } \\
\text { Abs/rel }\end{array}$ \\
\hline CALIOP Version 2 & & & & & & & \\
\hline Comparison \#1 & 0.154 & 0.156 & $-0.002 / 0.316$ & 40742 & 0.022 & $1.440 /-0.065$ & $0.316 / 205.0 \%$ \\
Comparison \#2 & 0.154 & 0.110 & $0.044 / 0.136$ & 40650 & 0.111 & $1.100 /-0.060$ & $0.143 / 93.0 \%$ \\
Comparison \#3 & 0.126 & 0.123 & $0.003 / 0.103$ & 6645 & 0.411 & $1.290 /-0.040$ & $0.103 / 81.5 \%$ \\
Comparison \#4 & 0.142 & 0.121 & $0.021 / 0.077$ & 2344 & 0.691 & $1.255 /-0.057$ & $0.079 / 55.8 \%$ \\
\hline CALIOP Version 3 & & & & & & & \\
\hline Comparison \#1 & 0.142 & 0.104 & $0.038 / 0.136$ & 267050 & 0.185 & $1.320 /-0.084$ & $0.142 / 99.6 \%$ \\
Comparison \#2 & 0.143 & 0.099 & $0.044 / 0.095$ & 258462 & 0.313 & $1.022 /-0.048$ & $0.105 / 73.6 \%$ \\
Comparison \#3 & 0.131 & 0.098 & $0.033 / 0.080$ & 206608 & 0.425 & $1.148 /-0.052$ & $0.087 / 66.2 \%$ \\
Comparison \#4 & 0.133 & 0.097 & $0.036 / 0.072$ & 42350 & 0.625 & $1.088 /-0.048$ & $0.081 / 60.9 \%$ \\
\hline
\end{tabular}



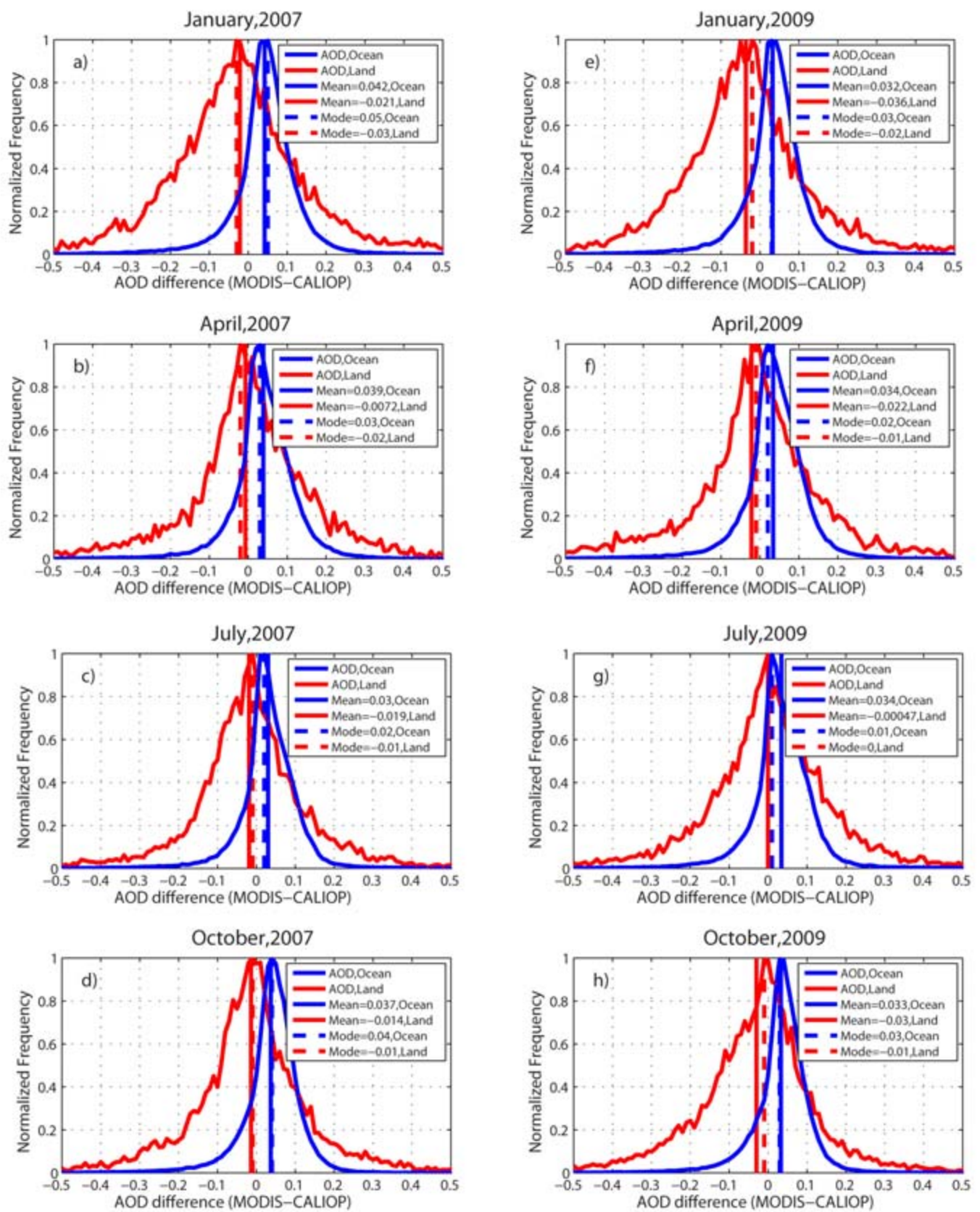

Fig. 5. (a) Frequency distributions of the difference between instantaneously collocated AOD retrievals of MODIS and CALIOP V 3 for January 2007. Blue lines represent over-ocean comparisons; red lines represent over-land comparisons. Solid vertical lines indicate the mean and dashed vertical lines indicate the mode of the frequency distribution. (b)-(h) same (a), but for different months in 2007 and 2009.

\section{Conclusions}

In this paper, we present a general consistency analysis between MODIS and CALIOP V2 and V3 AOD. We use only instantaneously collocated retrievals by the two sensors. A quantitative comparison of the agreement between MODIS and CALIOP V2 AOD on one hand and MODIS and CALIOP V3 AOD on the other is difficult, because of differ- ing spatial sampling of the MODIS data that are compared to the CALIOP data. Our analysis of the most suitable comparison scale showed that using $12 \times 12 \mathrm{~km}^{2}$ boxes around the CALIOP V3 retrievals resulted in optimal number of collocations with minimal impact of spatial variability in aerosol properties on the data comparison. Specifically, we found a steady increase in the rms difference between MODIS and CALIOP V3 AOD when going from $11 \times 11 \mathrm{~km}^{2}$ boxes to 

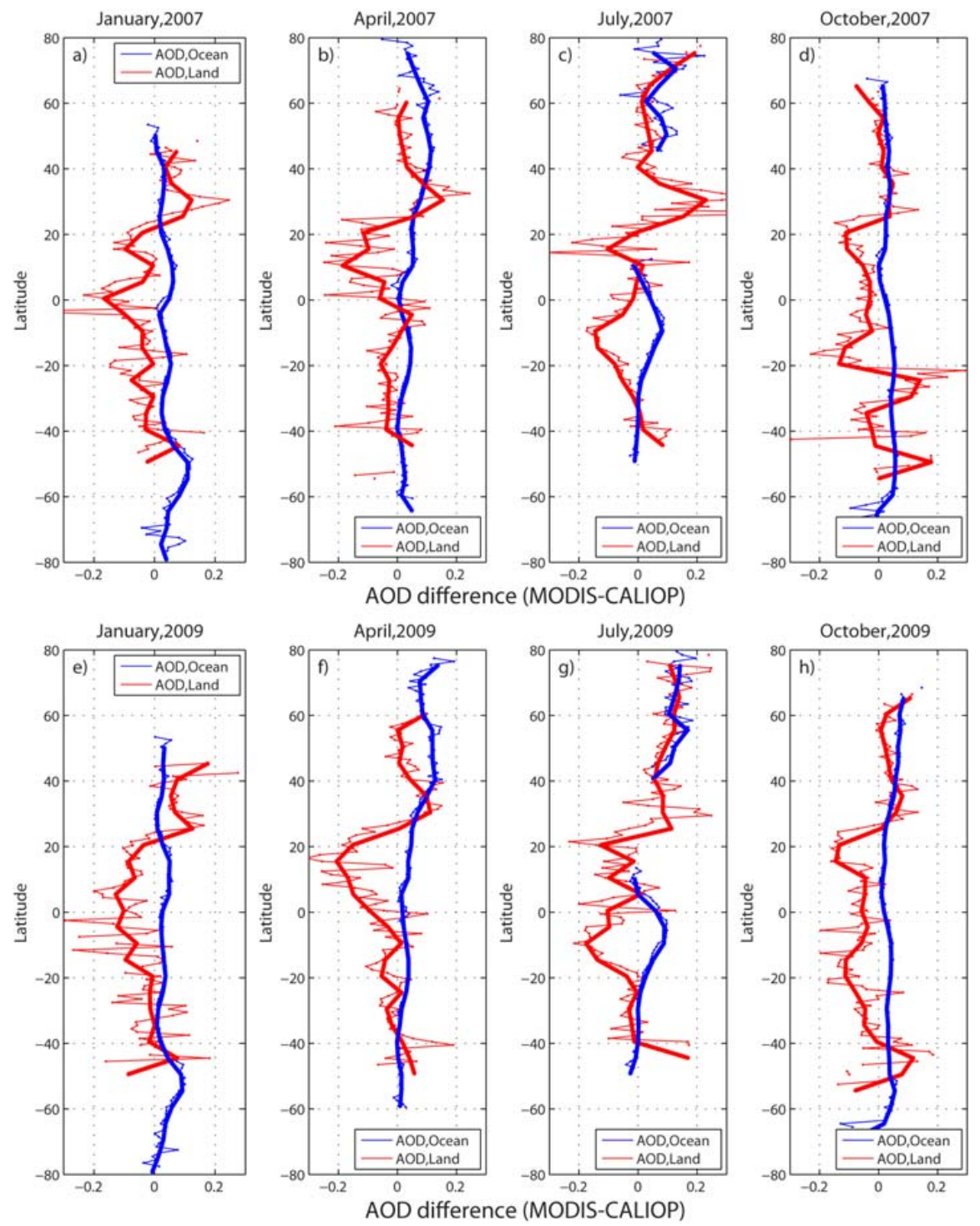

Fig. 6. Latitudinal distribution of the mean difference between MODIS and CALIOP V3 AOD (using comparison \# 3 screening from Table 1) over-ocean (blue lines) and over-land (red lines), with thin lines representing 1-degree averages and thick lines indicating 5-degree averages, for all 8 months considered in this study.

$15 \times 15 \mathrm{~km}^{2}$ boxes. However, there was a significant drop in the number of collocated retrievals when we went from $12 \times 12 \mathrm{~km}^{2}$ boxes to $11 \times 11 \mathrm{~km}^{2}$ boxes, hence our choice of $12 \times 12 \mathrm{~km}^{2}$ boxes. The steady increase in rms difference between the two sensors' AOD leads us to conclude that there is a finite rms difference caused by the spatial variability of aerosol properties, as is the case for any comparison of AOD retrievals based on data from sensors with different spatial and temporal sampling (Shinozuka and Redemann, 2011).

In general, we find increased data density and equal or better agreement of CALIOP V3 than CALIOP V2 when compared to MODIS AOD over-ocean. A restriction to data with MODIS aerosol quality flag (Quality_Assurance_Ocean) of
1-3, CALIOP extinction retrievals that fall within the "valid range" of 0 to $1.25 \mathrm{~km}^{-1}$, eliminating CALIOP profiles for which any extinction retrievals have quality flags different from 0,1 or 2, and CALIOP extinction profiles that have collocated cloud optical depths equal to zero, yields the strongest correlation between the MODIS and CALIOP derived AOD (without restricting the comparisons to severely cloud-free cases). The valid range for $532 \mathrm{~nm}$ extinction retrievals of 0 to $1.25 \mathrm{~km}^{-1}$ was an arbitrary choice and is partially being validated here. We analyzed in situ observations of aerosol extinction in airborne field campaigns (ARCTAS) and found that less than $1 \%$ of observations are greater than $1.25 \mathrm{~km}^{-1}$, even when heavy aerosol loadings are sought 

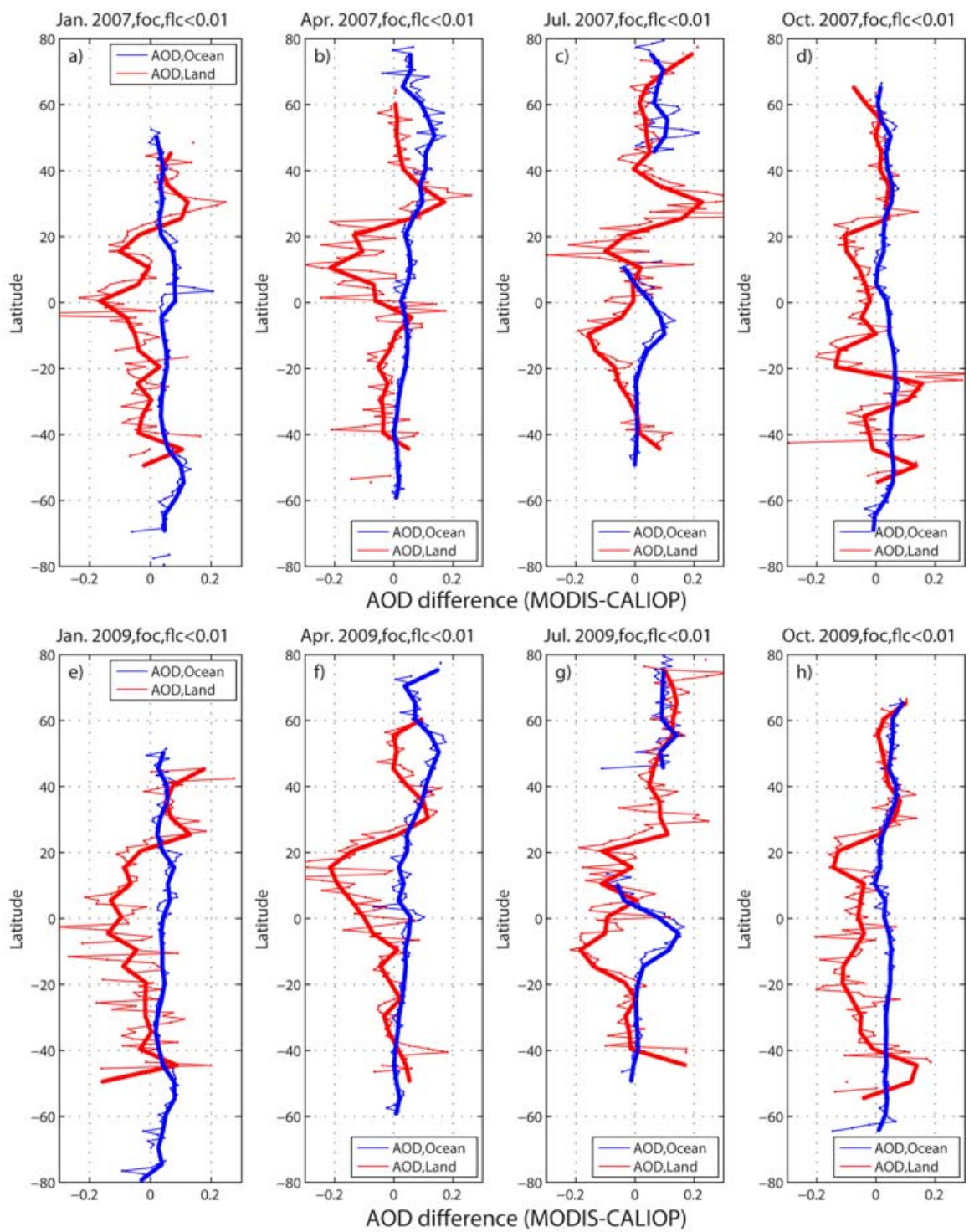

Fig. 7. Same as Fig. 6, but for the more severely cloud-screened data, as described by comparison \# 4 in Table 1 . foc: cloud fraction over ocean; flc: cloud fraction over land.

after on the aircraft. The global CALIOP observations have a greater than $1 \%$ occurrence of extinctions greater than $1.25 \mathrm{~km}^{-1}$. This seems unrealistic based on the in situ observations, but how unrealistic is difficult to assess with regional in situ observations. To our knowledge, requiring the extinction retrievals to fall into the range of 0 to $1.25 \mathrm{~km}^{-1}$ does not exclude specific aerosol types, but instead only unrealistically large aerosol loadings of any type.

We found no utility of filtering the CALIOP aerosol extinction data using the uncertainty estimates included in CALIOP V3 retrievals, i.e., the MODIS-CALIOP AOD comparisons using the filters described in Table 1, comparison \#3, could not be improved upon by use of CALIOP extinction uncertainties. A restriction to scenes with cloud fractions less than $1 \%$ (as defined in the MODIS aerosol retrievals) generally results in improved correlation $\left(R^{2}>0.5\right)$. This improvement is probably due to the improved performance of the passive MODIS retrievals in the absence of clouds, and also due to the improved performance of the CALIOP retrievals where no aerosol-cloud discrimination needs to be performed.

In absolute terms, the comparison between the two data sets still yields rms differences of 0.1 , which may be too large for many applications that attempt to combine these data sets quantitatively. An rms difference of this magnitude points to the fact that there is limited probability that individ- 

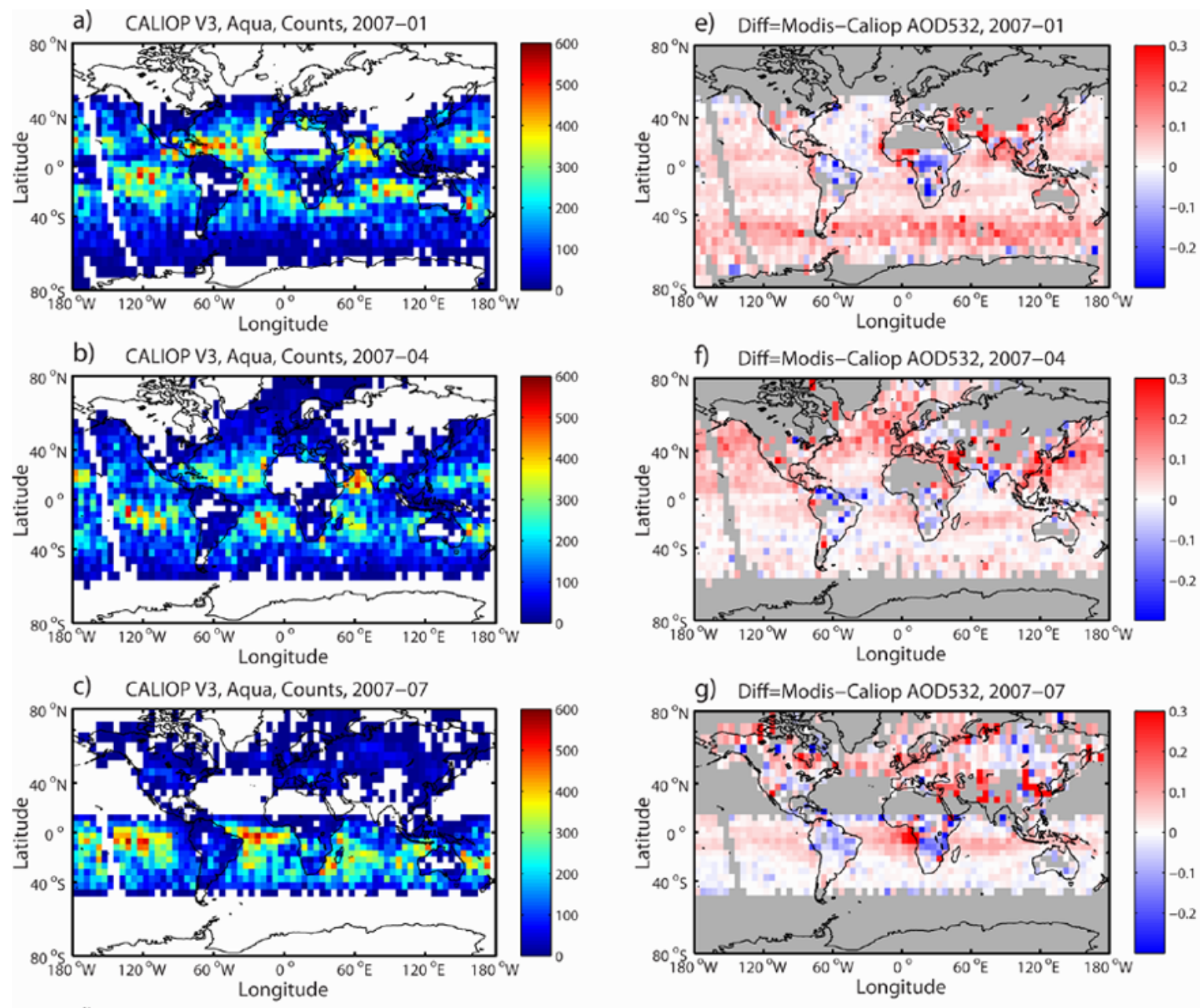

d) CALIOP V3, Aqua, Counts, 2007-10

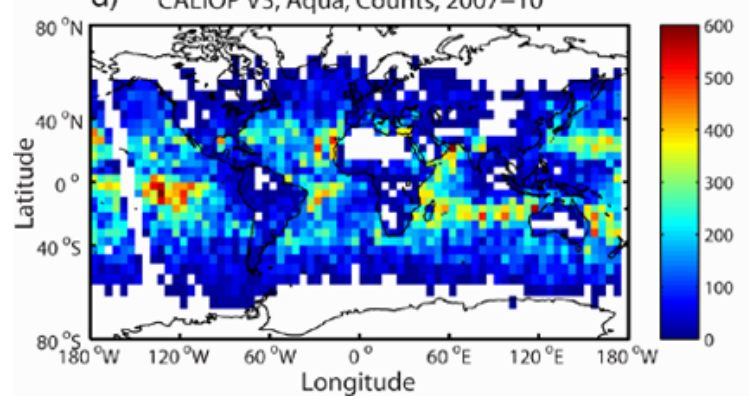

h) Diff=Modis-Caliop AOD532, 2007-10

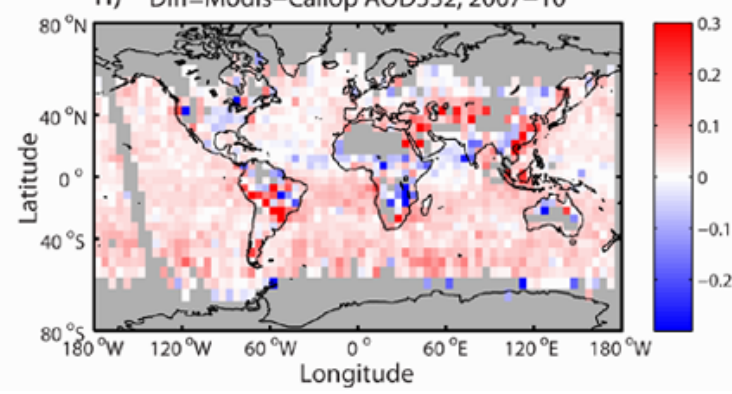

Fig. 8. (a) Global distribution of the number of instantaneously collocated MODIS versus CALIOP V 3 AOD comparisons in $5 \times 5$ degree boxes for January 2007. (e) Global distribution of the mean difference between instantaneously collocated MODIS and CALIOP V3 AOD retrievals for January 2007. (b)-(d) same as (a), but for April, July, and October of 2007. (f)-(h) same as (e), but for April, July, and October of 2007.

ual measurement pairs from the two sensors can be used in combination to make further deductions about aerosol type or origin. It should be noted that some fraction of this rms difference is due to the fact that CALIOP only estimates aerosol properties in those regions where it "detects" an aerosol layer. In regions where aerosol layers are more tenuous, i.e., distributed over greater geometric depth, CALIOP likely fails to detect such aerosol layers, contributing to the rms difference found here. This is corroborated by independent aircraft validation exercises in the ARCTAS experiment (Redemann et al., 2009b). The geographical distribution of over-ocean AOD difference shows latitudinally averaged differences of generally less than 0.05 , although some latitude bands with 0.1 AOD differences occur. These bands can often be traced 
a) CALIOP V3, Aqua, Counts, 2009-01

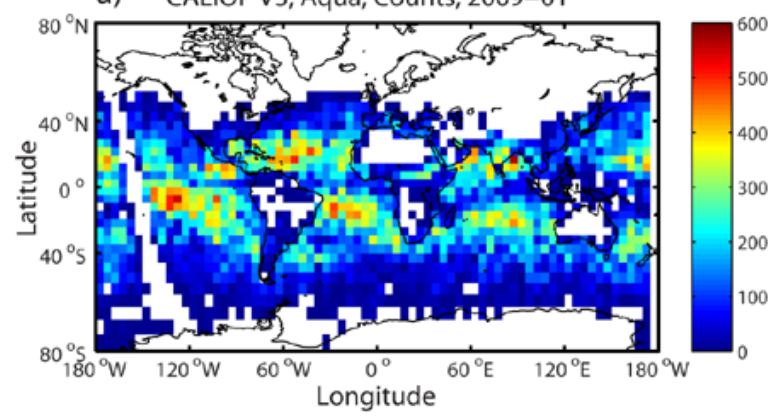

b) CALIOP V3, Aqua, Counts, 2009-04

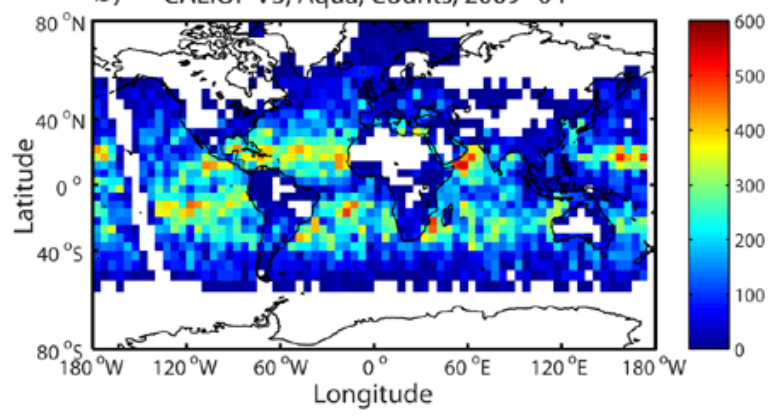

C) CALIOP V3, Aqua, Counts, 2009-07

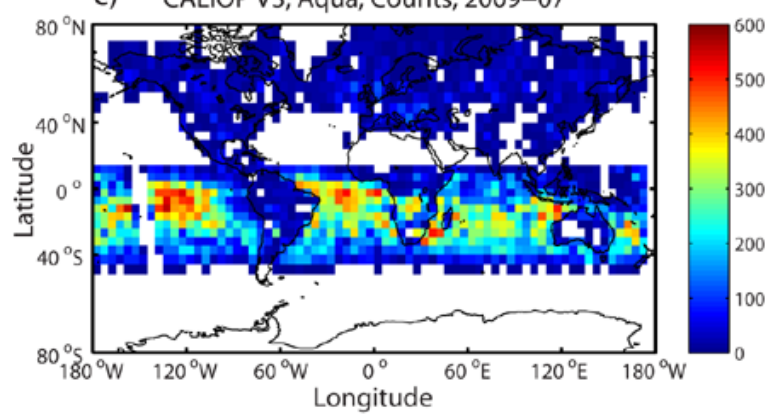

d) CALIOP V3, Aqua, Counts, 2009-10

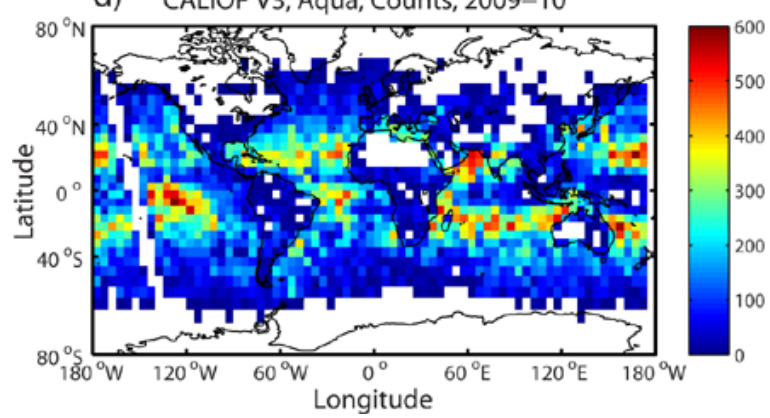

Fig. 9. Same as Fig. 8, but for data collected in 2009.

to regional AOD difference hot spots, for example in Asian outflow during April and African outflow into the Atlantic Ocean basin during July. We find no statistically significant difference in the consistency between MODIS and CALIOP V2/V3 between 2007 and 2009, leading to the conclusion that sensor calibration and performance did not change significantly between 2007 and 2009. As stated in the introduction, the study presented here is worthwhile because the e) Diff=Modis-Caliop AOD532, 2009-01
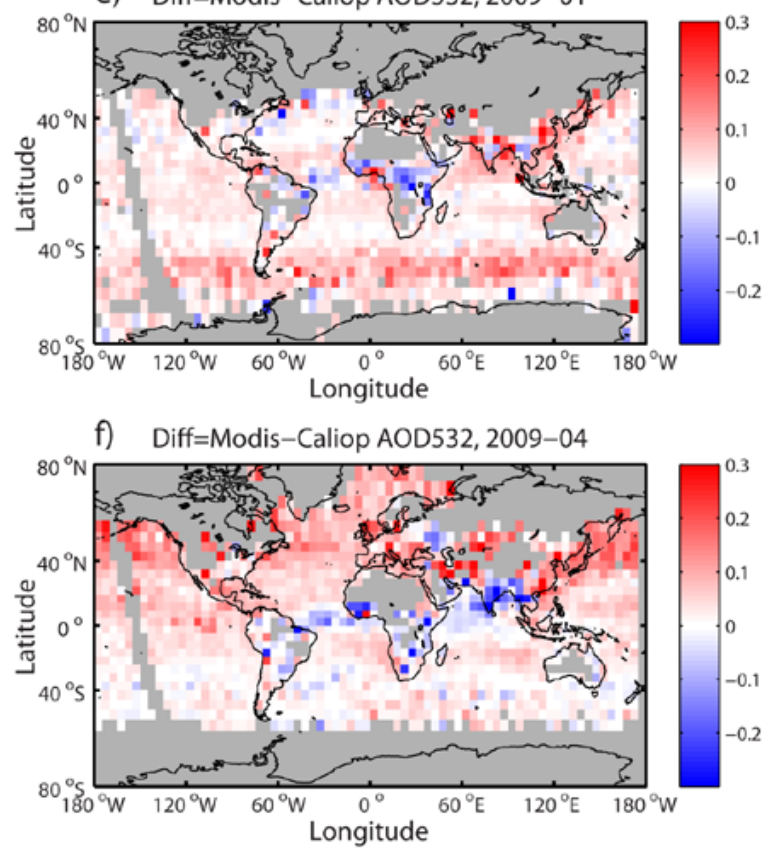

g) Diff=Modis-Caliop AOD532, 2009-07

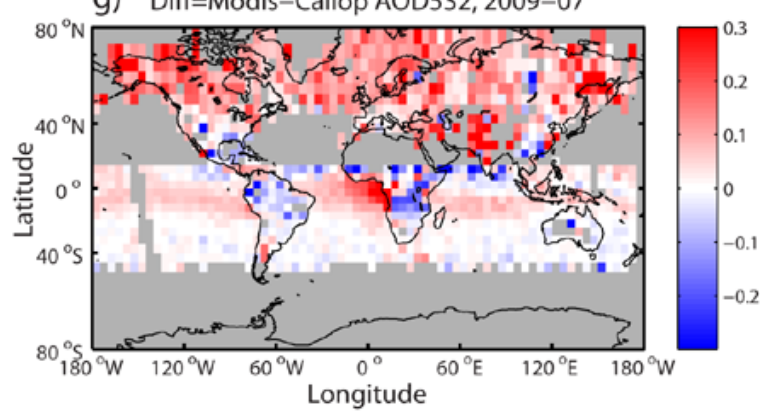

h) Diff=Modis-Caliop AOD532, 2009-10

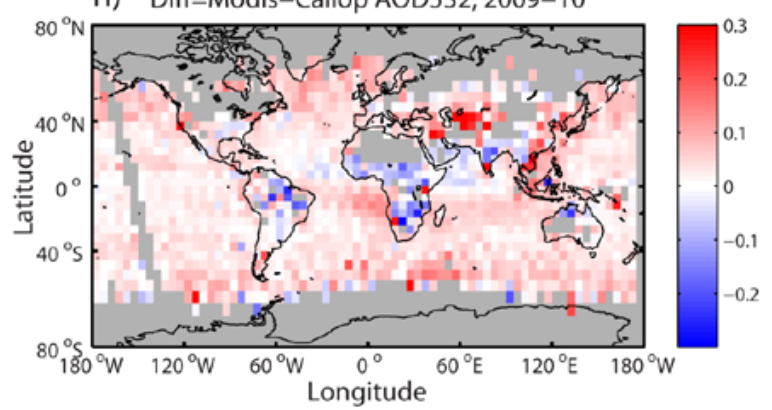

MODIS over-ocean AOD retrieval uncertainty is reasonably well documented in the literature, and because few other opportunities exist to assess CALIOP AOD retrieval quality. However, our study is hampered by the necessary use of CALIOP daytime data and by the imperfect collocation of sampling between the two sensors. The latter is a limitation that is inherent to all data comparisons with different spatial sampling, but that should only matter if spatial variability of 
AOD is large. Future studies to assess CALIOP data quality using specifically designed suborbital observations and CALIOP nighttime retrievals should be encouraged.

Acknowledgements. This study was partially supported by CALIPSO ST funding under NASA grant NNX10AN60G. We would like to thank the MODIS and CALIOP algorithm development teams for their efforts in providing and discussing these data sets.

Edited by: J. Quaas

\section{References}

Bréon, F.-M., Vermeulen, A., and Descloitres, J.: An evaluation of satellite aerosol products against sunphotometer measurements, Remote Sens. Environ., 115, 3102-3111, 2011.

Hu, Y., Winker, D., Vaughan, M., Lin, B., Omar, A., Trepte, C., Flittner, D., Yang, P., Nasiri, S. L., Baum, B., Holz, R., Sun, W., Liu, Z., Wang, Z., Young, S., Stamnes, K., Huang, J., Kuehn, R.: CALIPSO/CALIOP Cloud Phase Discrimination Algorithm, J. Atmos. Oceanic Technol., 26, 2293-2309, http://dx.doi.org/10.1175/2009JTECHA1280.1, 2009.

Huang, J., Hsu, N. C., Tsay, S.-C., Jeong, M.-J., Holben, B. N., Berkoff, T. A., and Welton, E. J.: Susceptibility of aerosol optical thickness retrievals to thin cirrus contamination during the BASE-ASIA campaign, J. Geophys. Res., 116, D08214, doi:10.1029/2010JD014910, 2011.

Hunt, W. H., Winker, D. M., Vaughan, M. A., Powell, K. A., Lucker, P. L., and Weimer, C.: CALIPSO Lidar Description and Performance Assessment, J. Atmos. Oceanic Technol., 26, 1214-1228, doi:10.1175/2009JTECHA1223.1, 2009.

IPCC-2007: Contribution of Working Groups I, II and III to the Fourth Assessment Report of the Intergovernmental Panel on Climate Change, edited by: Core Writing Team, Pachauri, R. K. and Reisinger, A., IPCC, Geneva, Switzerland, 2007.

Jeong, M.-J. and Hsu, N. C.: Retrievals of aerosol single-scattering albedo and effective aerosol layer height for biomass-burning smoke: Synergy derived from “A-Train" sensors, Geophys. Res. Lett., 35, L24801, doi:10.1029/2008GL036279, 2008.

Jones, T. A. and Christopher, S. A.: Statistical properties of aerosol-cloud-precipitation interactions in South America, Atmos. Chem. Phys., 10, 2287-2305, doi:10.5194/acp-10-22872010, 2010.

Kacenelenbogen, M., Vaughan, M. A., Redemann, J., Hoff, R. M., Rogers, R. R., Ferrare, R. A., Russell, P. B., Hostetler, C. A., Hair, J. W., and Holben, B. N.: An accuracy assessment of the CALIOP/CALIPSO version 2/version 3 daytime aerosol extinction product based on a detailed multi-sensor, multiplatform case study, Atmos. Chem. Phys., 11, 3981-4000, doi:10.5194/acp-11-3981-2011, 2011.

Kahn, R. A., Gaitley, B. J., Martonchik, J. V., Diner, D. J., Crean, K. A., and Holben, B.: Multiangle Imaging Spectroradiometer (MISR) global aerosol optical depth validation based on 2 years of coincident Aerosol Robotic Network (AERONET) observations, J. Geophys. Res., 110, D10S04, doi:10.1029/2004JD004706, 2005.
Kahn, R. A., Gaitley, B. J., Garay, M. J., Diner, D. J., Eck, T., Smirnov, A., and Holben, B. N.: MISR global aerosol product assessment by comparison with Aerosol Robotic Network, J. Geophys. Res., 115, D23209, doi:10.1029/2010JD014601, 2010.

Kaufman, Y., Tanré, D., and Boucher, O.: A satellite view of aerosols in the climate system, Nature, 419, 215-223, 2002.

Kittaka, C., Winker, D. M., Vaughan, M. A., Omar, A., and Remer, L. A.: Intercomparison of column aerosol optical depths from CALIPSO and MODIS-Aqua, Atmos. Meas. Tech., 4, 131-141, doi:10.5194/amt-4-131-2011, 2011.

Kleidman, R. G., Smirnov, A., Levy, R. C., Mattoo, S., and Tanre, D.: Evaluation and wind speed dependence of MODIS aerosol retrievals over open ocean, IEEE T. Geosci. Remote, 50, 429435, 2012.

Levy, R. C., Remer, L. A., Kleidman, R. G., Mattoo, S., Ichoku, C., Kahn, R., and Eck, T. F.: Global evaluation of the Collection 5 MODIS dark-target aerosol products over land, Atmos. Chem. Phys., 10, 10399-10420, doi:10.5194/acp-10-10399-2010, 2010.

Liu, Z., Kuehn, R., Vaughan, M., Winker, D., Omar, A., Powell, K., Trepte, C., Hu, Y., and Hostetler, C.: The CALIPSO Cloud and Aerosol Discrimination: Version 3 Algorithm and Test Results, 25th International Laser Radar Conference (ILRC), St. Petersburg, Russia, ISBN 978-5-94458-109-9, 2010.

Livingston, J. M., Redemann, J., Russell, P. B., Torres, O., Veihelmann, B., Veefkind, P., Braak, R., Smirnov, A., Remer, L., Bergstrom, R. W., Coddington, O., Schmidt, K. S., Pilewskie, P., Johnson, R., and Zhang, Q.: Comparison of aerosol optical depths from the Ozone Monitoring Instrument (OMI) on Aura with results from airborne sunphotometry, other space and ground measurements during MILAGRO/INTEX-B, Atmos. Chem. Phys., 9, 6743-6765, doi:10.5194/acp-9-6743-2009, 2009.

Martins, J. V., Tanré, D., Remer, L. A., Kaufman, Y. J., Mattoo, S., and Levy, R.: MODIS Cloud screening for remote sensing of aerosol over oceans using spatial variability, Geophys. Res. Lett., 29, doi:10.1029/2001GL013252, 2002.

Matichuk, R. I., Colarco, P. R., Smith, J. A., and Toon, O. B.: Modeling the transport and optical properties of smoke plumes from South American biomass burning, J. Geophys. Res., 113, D07208, doi:10.1029/2007JD009005, 2008.

Myhre, G.: Consistency between satellite-derived and modeled estimates of the direct aerosol effect, Science, 325, doi:10.1126/science.1174461, 2009.

Omar, A. H., J. Won, D. M. Winker, S. Yoon, O. Dubovik, and M. P. McCormick, Development of global aerosol models using cluster analysis of Aerosol Robotic Network (AERONET) measurements, J. Geophys. Res., 110, D10S14, doi:10.1029/2004JD004874, 2005.

Omar, A. H., Winker, D. M., Vaughan, M. A., Hu, Y., Trepte, C. R., Ferrare, R. A., Lee, K.-P., Hostetler, C. A., Kittaka, C., Rogers, R. R., Kuehn, R. E., and Liu, Z.: The CALIPSO Automated Aerosol Classification and Lidar Ratio Selection Algorithm, J. Atmos. Oceanic Technol., 26, 1994-2014, doi:10.1175/2009JTECHA1231.1, 2009.

Oo, M. and Holz, R.: Improving the CALIOP aerosol optical depth using combined MODIS-CALIOP observations and CALIOP integrated attenuated total color ratio, J. Geophys. Res., 116, D14201, 15 pp., doi:10.1029/2010JD014894, 2011.

Peyridieu, S., Chédin, A., Tanré, D., Capelle, V., Pierangelo, C., 
Lamquin, N., and Armante, R.: Saharan dust infrared optical depth and altitude retrieved from AIRS: a focus over North Atlantic comparison to MODIS and CALIPSO, Atmos. Chem. Phys., 10, 1953-1967, doi:10.5194/acp-10-1953-2010, 2010.

Powell, K. A., Vaughan, M. A., Rogers, R. R., Kuehn, R. E., Hunt, W. H., Lee, K.-P., and Murray, T. D.: The CALIOP 532-nm Channel Daytime Calibration: Version 3 Algorithm Proceedings of the 25th International Laser Radar Conference, 1367-1370, ISBN 978-5-94458-109-9, 2010.

Redemann, J., Schmid, B., Eilers, J. A., Kahn, R. A., Levy, R. C., Russell, P. B., Livingston, J. M., Hobbs, P. V., Smith Jr., W. L., and Holben, B. N.: Suborbital measurements of spectral aerosol optical depth and its variability at sub-satellite grid scales in support of CLAMS, 2001, J. Atmos. Sci. , doi:10.1175/JAS3387.1, 62, 993-1007, 2005.

Redemann, J., Zhang, Q., Schmid, B., Russell, P. B., Livingston, J. M., Jonsson, H., and Remer, L. A.: Assessment of MODISderived visible and near-IR aerosol optical properties and their spatial variability in the presence of mineral dust, Geophys. Res. Lett., 33, L18814, doi:10.1029/2006GL026626, 2006.

Redemann, J., Pilewskie, P., Russell, P. B., Livingston, J. M., Howard, S., Schmid, B., Pommier, J., Gore, W., Eilers, J., and Wendisch, M.: Airborne measurements of spectral direct aerosol radiative forcing in the Intercontinental chemical Transport Experiment/Intercontinental Transport and Chemical Transformation of anthropogenic pollution, 2004, J. Geophys. Res., 111, D14210, doi:10.1029/2005JD006812, 2006.

Redemann, J., Zhang, Q., Russell, P. B., Livingston, J. M., and Remer, L. A.: Case studies of aerosol remote sensing in the vicinity of clouds, J. Geophys. Res., 114, D06209, doi:10.1029/2008JD010774, 2009a.

Redemann, J., Livingston, J., Shinozuka, Y., Russell, P., Zhang, Q., Johnson, R., Ramachandran, S., Clarke, A., McNaughton, C., and Veheilmann, B.: Airborne sunphotometer (AATS-14) measurements in ARCTAS - first insights into their combined use with satellite observations to study Arctic aerosol radiative effects, ARCTAS Science Team Meeting, Virginia Beach, VA, January $27,2009 b$.

Redemann, J., Zhang, Q., Livingston, J., Russell, P., Shinozuka, Y., Clarke, A., Johnson, R., and Levy, R.: Testing aerosol properties in MODIS Collection 4 and 5 using airborne sunphotometer observations in INTEX-B/MILAGRO, Atmos. Chem. Phys., 9, 8159-8172, doi:10.5194/acp-9-8159-2009, 2009c.

Remer, L. A., Kaufman, Y. J., Tanré, D., Mattoo, S., Chu, D. A., Martins, J. V., Li, R.-R., Ichoku, C., Levy, R. C., Kleidman, R. G., Eck, T. F., Vermote, E., and Holben, B. N.: The MODIS aerosol algorithm, products and validation, J. Atmos. Sci., 62, 947-973, 2005.

Remer, L. A., Kleidman, R. G., Levy, R. C., Kaufman, Y. J., Tanre, D., Mattoo, S., Martins, J. V., Ichoku, C., Koren, I., Yu, H. B., Holben, B. N.: Global aerosol climatology from the MODIS satellite sensors, J. Geophys. Res., 113, D14S07, doi:10.1029/2007JD009661, 2008.

Russell, P. B., Livingston, J. M., Redemann, J., Schmid, B., Ramirez, S. A., Eilers, J., Kahn, R., Chu, A., Remer, L., Quinn, P. K., Rood, M. J., and Wang, W.: Multi-gridcell validation of satellite aerosol property retrievals in INTEX/ITCT/ICARTT 2004, J. Geophys. Res., 112, D12S09, doi:10.1029/2006JD007606, 2007.
Satheesh, S. K., Torres, O., Remer, L. A., Babu, S. S., Vinoj, V., Eck, T. F., Kleidman, R. G., and Holben, B. N.: Improved assessment of aerosol absorption using OMI-MODIS joint retrieval, J. Geophys. Res., 114, D05209, doi:10.1029/2008JD011024, 2009.

Shinozuka, Y. and Redemann, J.: Horizontal variability of aerosol optical depth observed during the ARCTAS airborne experiment, Atmos. Chem. Phys., 11, 8489-8495, doi:10.5194/acp-11-84892011, 2011.

Schuster, G., MacDonnell, D., and Trepte, C.: Can AERONET ground sites be used to validate CALIPSO aerosol products, CALIPSO ST meeting, 2007.

Sokal, R. R. and Rohlf, F. J.: Biometry, 3rd edn., W.H. Freeman and Co., New York, USA, 1995.

Torres, O., Tanskanen, A., Veihelmann, B., Ahn, C., Braak, R., Bhartia, P.K., Veefkind, P., and Levelt, P.: Aerosols and surface UV products from Ozone Monitoring Instrument observations: An overview, J. Geophys. Res., 112, D24S47, doi:10.1029/2007JD008809, 2007.

Vaughan, M., Kuehn, R., Tackett, J., Rogers, R., Liu, Z., Omar, A., Getzewich, B., Powell, K., Hu, Y., Young, S., Avery, M., Winker, D., and Trepte, C.: Strategies for Improved CALIPSO Aerosol Optical Depth Estimates, Proceedings of the 25th International Laser Radar Conference, 1340-1343, ISBN 978-5-94458-109-9, 2010.

Winker, D. M., Hunt, W. H., and McGill, M. J.: Initial performance assessment of CALIOP, Geophys. Res. Lett., 34, L19803, doi:10.1029/2007GL030135, 2007.

Winker, D. M., Vaughan, M. A., Omar, A. H., Hu, Y., Powell, K. A., Liu, Z., Hunt, W. H., and Young, S. A.: Overview of the CALIPSO Mission and CALIOP Data Processing Algorithms, J. Atmos. Oceanic Technol., 26, 2310-2323, doi:10.1175/2009JTECHA1281.1, 2009.

Winker, D. M., Pelon, J., Coakley Jr., J. A., Ackerman, S. A., Charlson, R. J., Colarco, P. R., Flamant, P., Fu, Q., Hoff, R. M., Kittaka, C., Kubar, T. L., Le Treut, H., McCormick, M. P., Mégie, G., Poole, L., Powell, K., Trepte, C., Vaughan, M. A., and Wielicki, B. A.: The CALIPSO Mission: A Global 3D View Of Aerosols And Clouds, Bull. Am. Meteorol. Soc., 91, 1211-1229, doi:10.1175/2010BAMS3009.1, 2010.

Young, S. A. and Vaughan, M. A.: The retrieval of profiles of particulate extinction from Cloud Aerosol Lidar Infrared Pathfinder Satellite Observations (CALIPSO) data: Algorithm description, J. Atmos. Oceanic Technol., 26, 1105-1119, doi:10.1175/2008 JTECHA1221.1. 2009.

Young, S. A., Winker, D. M., Vaughan, M. A., Hu, Y., and Kuehn, R. E.: CALIOP Algorithm Theoretical Basis Document - Part 4: Extinction Retrieval Algorithms, Release 1.0 (DRAFT), PCSCI-202 Part 4, available at: http://www-calipso.larc.nasa.gov/ resources/pdfs/PC-SCI-202_Part4_v1.0.pdf, 2008.

Zhang, J., Christopher, S. A., Remer, L. A., and Kaufman, Y. J.: Shortwave Aerosol Cloud-Free Radiative Forcing from Terra, II: Global and Seasonal Distributions, J. Geophys. Res., D10, S24, doi:10.1029/2004jd005009, 2005. 